\title{
Physical Aspects of Cell Culture Substrates: Topography, Roughness, and Elasticity
}

\author{
Aftin M. Ross, Zhongxiang Jiang, Martin Bastmeyer, and Joerg Lahann*
}

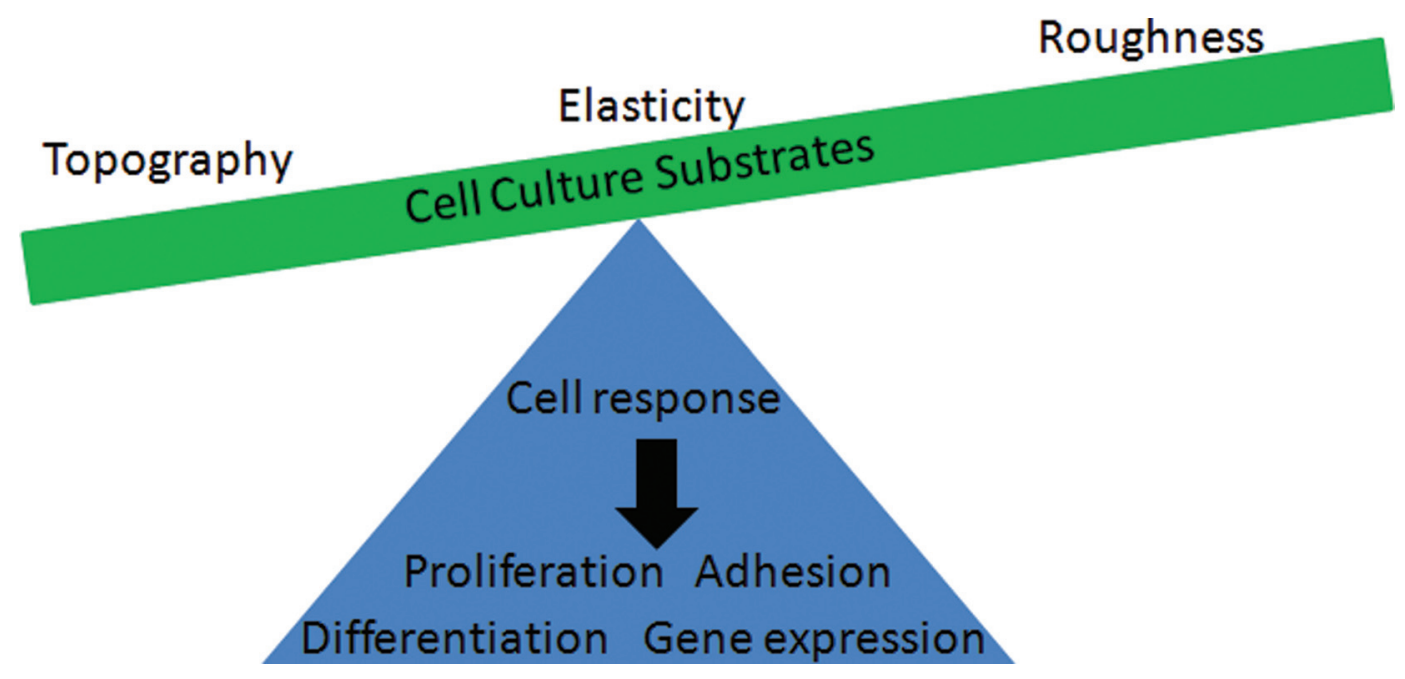

\section{From the Contents}

1. Introduction

2. Topography and Roughness

3. Elasticity

4. Summary \& Outlook
337 337

.341 352 


\section{Introduction}

Cellular responses to environmental cues can result in intercellular and intracellular changes in cytoskeletal organization, proliferation, cell differentiation, gene expression, and apoptosis. ${ }^{[1-3]}$ In addition to the biochemical properties of the extracellular matrix $(\mathrm{ECM}),{ }^{[4]}$ cells can sense underlying substrates with respect to physical properties such as elasticity, topography, gradients, and geometrical changes. ${ }^{[5-8]}$ In vivo, cells encounter signaling from protein folding and ECM binding. ${ }^{[5]}$ Cascades of sensing processes are of fundamental importance in cell biology, tissue engineering, and medicine. However, cellular interactions with environments occur both in vivo and in vitro. In particular, interactions with synthetic surfaces are of increasing significance, as they are utilized to mimic in vivo conditions for a wealth of healthcare applications. ${ }^{[9]}$ Herein, we focus on physical aspects of synthetic surfaces in vitro, namely surface topography, roughness, and elasticity.

The topography of synthetic surfaces may be altered using a myriad of techniques, such as photolithography, ${ }^{[10]}$ electron beam lithography, ${ }^{[11]}$ and soft lithography. ${ }^{[12]}$ These techniques alter material properties on the micrometer and nanometer scale including surface roughness. Surface topography, roughness, and elasticity of tissues within the body are variable and these deviations may serve as a blueprint for cellular function in vitro. For example, properties such as roughness provide adhesion and alignment cues for endothelial cells and elasticity induces changes in cell morphology. ${ }^{[13]}$ The aforementioned physical cues also determine stem cell fate. ${ }^{[14,15]}$ Stem cells have a multitude of therapeutic applications including the treatment of macular degeneration ${ }^{[16]}$ and osteoporosis. ${ }^{[17]}$ Therefore an understanding of how the physical environment influences stem cell behavior would be highly beneficial and synthetic substrates provide this opportunity.

This review highlights recent developments in the modulation of the physical aspects of synthetic surfaces, their impacts for in vitro cellular signaling responses, as well as the potential and limitations towards practical uses in biotechnology in vitro. As cellular responses to physical cues may vary based on cell type, the influence of various surface characteristics is described for a range of different cell types. In addition, the modification of a wide range of biomaterials from metals to polymers is discussed.

\section{Topography and Roughness}

The impact of substrate topography on cell behavior is a widely investigated physical cue. ${ }^{[18-22]}$ Topography is important in development, and natural regeneration occurs when cells grow on topography provided by other cells and extracellular matrix. ${ }^{[23]}$ Diverse techniques have been employed to fabricate topographical substrates in the micro- and nanometer range, such as two-photon polymerization, ${ }^{[24,25]}$ soft lithography, ${ }^{[26,27]}$ capillary force lithography, ${ }^{[28]}$ photolithography, ${ }^{[29,30]}$ UV-assisted capillary molding, ${ }^{[31]}$ and micromachining. ${ }^{[32]}$ Suitable base substrates include a wide range of materials, from tissue culture plastics, polymers such as poly(dimethylsiloxane) (PDMS), poly(methyl methacrylate) (PMMA), and Ormocer, ${ }^{[24,25]}$ to silicon oxide and metals. ${ }^{[32]}$ Research on these substrates reveal the influence of topography for controlling cell functions such as cytoskeletal organization, adhesion, polarization, migration, proliferation, and differentiation. The topographical substrates discussed herein predominantly have a defined pattern with variable height/depth and width and a diverse form of anisotropy and stiffness.

\subsection{Topography of Soft Materials}

Polymers are commonly utilized in the biomedical field as scaffolds for tissue engineering, ${ }^{[33]}$ shells for drug delivery, ${ }^{[34]}$ and coatings for medical implants, such as cardiovascular stents. ${ }^{[35]}$ Therefore the surface topography of these materials plays a role in cellular behavior as cells directly interact with these surfaces.

As more is learned about physical cellular cues, there is increasing interest in evaluating topographical influence on the nanoscale. To date, nanoscale topography has been found to impact a host of cellular behaviors including proliferation, differentiation, and gene expression. ${ }^{[36]}$ Nanogrooves and nanogratings are commonly employed nanotopographical elements for exploring cell-surface interactions. Traditionally, nanogratings have consisted of one pattern height per platform. ${ }^{[37]}$ Recently, Sun et al. improved upon existing methods by generating a continuous nanograting system consisting of numerous heights and shapes. ${ }^{[37]}$ This new grating platform further allows for the fabrication of combinatorial

A. M. Ross, Prof. J. Lahann

Department of Biomedical Engineering

University of Michigan

Ann Arbor, MI 48109, USA

E-mail: lahann@umich.edu

Z. Jiang, Prof. M. Bastmeyer

Zoologisches Institut

Zell- und Neurobiologie

Karlsruhe Institute of Technology (KIT)

Haid-und-Neu-Straße 9, 76131 Karlsruhe, Germany

Z. Jiang, Prof. M. Bastmeyer

Center for Functional Nanostructures (CFN)

Karlsruhe Institute of Technology (KIT)

Wolfgang-Gaede-Str. 1a, 76131 Karlsruhe, Germany

Prof. J. Lahann

Department of Chemical Engineering

University of Michigan

Ann Arbor, MI 48109, USA

Prof. J. Lahann

Department of Macromolecular Sciences and Engineering

University of Michigan

Ann Arbor, MI 48109, USA

Prof. J. Lahann

Department of Materials Science and Engineering

University of Michigan

Ann Arbor, MI 48109, USA

DOI: 10.1002/smll.201100934 
topographical assessment substrates. Applications related to cell contact guidance and control of cell alignment can now be assessed.

Altomare et al. structured polymer surfaces to investigate the mechanism of skeletal muscle precursor formation of multinucleated myotubes. ${ }^{[38]}$ Microgrooves 5-100 $\mu \mathrm{m}$ in width and $0.5-5 \mu \mathrm{m}$ in depth were structured in a biodegradable poly-L-lactide/trimethylene carbonate copolymer (PLLA-TMC). In particular, grooves were created by solvent casting of the polymer onto silicon wafers, which were previously patterned via photolithography. $\mathrm{C} 2 \mathrm{C} 12$ myoblasts were seeded onto these surfaces, and cell behavior was evaluated in terms of cell fusion and myotube formation as well as alignment. At $24 \mathrm{~h}$, deeper and narrower grooves yielded better cell adhesion and proliferation. Conversely, at 7 days of culture, more shallow grooves, 0.5 and $1 \mu \mathrm{m}$ in depth, and wider grooves, those $>25 \mu \mathrm{m}$ in width, promoted more favorable myotube formation. ${ }^{[38]}$ These results indicate the need for prolonged cell culture studies to understand myotube formation on in vitro surfaces. Nonetheless, grooved substrates were found to induce cell alignment and myotube formation, which was influenced by groove dimensions (Figure 1). ${ }^{[38]}$ Nanogrooves have also induced alignment of osteoblast cells and their ECM. ${ }^{[39,40]}$ Applications of these works could influence investigations of neural regeneration and tissue engineering of the vascular endothelium, where cellular and matrix alignment is important.

Three-dimensional micropillars are another topographic feature that has been exploited to influence cellular interactions. Ghibaudo and colleagues generated micropillars to study fibroblast cell adhesion and migration as a function of surface topography. ${ }^{[41]}$ In this work, micropillars were created on PDMS substrates. Specifically, the PDMS was molded onto microstructured silicon wafers and pillars ranging from 2 to $10 \mu \mathrm{m}$ in height and from 5 to $10 \mu \mathrm{m}$ in diameter were produced. As compared to flat PDMS surfaces, cells on the structured surfaces demonstrated elongated shapes and had a branched morphology. The number of actin stress fibers, which is an indicator of cell adhesion, were less than those on flat substrates, but were aggregated around pillar edges indicating enhanced focal contacts. Pillar size and spacing also influenced cellular migration and increased migration, as compared to flat substrates. Increased cell motility on pillars, as compared to flat substrates, was attributed to the increase in the size and lifetime of the focal contacts at the pillar edges (Figure 2). Because cell types vary in their response to pillar topography, an application of this work is to distinguish between cell phenotypes based on response to the topographical surface.

The influence of polymer topography on cell behavior is highly dependent on the polymeric materials and cell types utilized. For example, Loesberg et al. found that nanogrooves in polystyrene less than $35 \mu \mathrm{m}$ in depth no longer provided contact guidance for fibroblast alignment. ${ }^{[42]}$ This contrasts Altomare's work with myoblasts, in which guidance occurred at depths from 0.5 to $5 \mu \mathrm{m}$ on a poly-L-lactide/trimethylene carbonate copolymer. ${ }^{[38]}$ These findings point towards a subtle interplay of chemistry and physics as well as a dependence on cell type. Nonetheless, the applicability of polymers

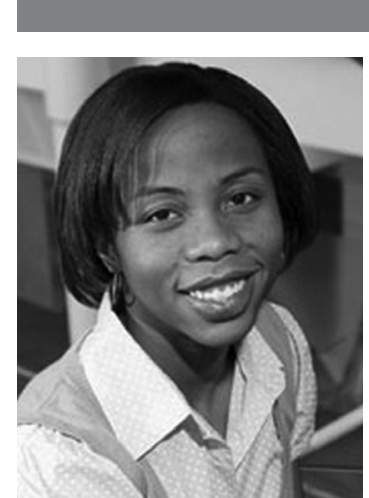

Aftin M. Ross is pursuing her Ph.D. in the Department of Biomedical Engineering at the University of Michigan, Ann Arbor where her thesis advisor is Joerg Lahann. She earned a MSE in Biomedical Engineering from the University of Michigan in 2009 and a BS in Mechanical Engineering from the University of Maryland Baltimore County (UMBC) in 2007. Her current research interests include the design and modification of reactive coatings for sensing and cell culture applications through the use of polymer grafting, atom transfer radical polymerization (ATRP), click chemistry, and various immobilization strategies.

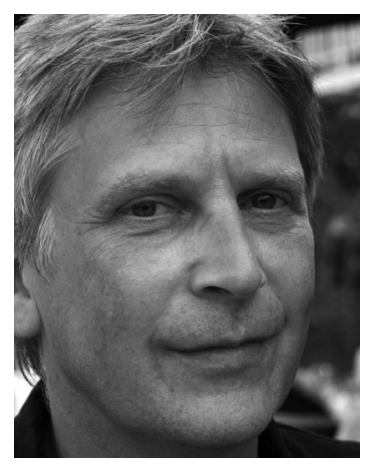

Martin Bastmeyer is a Professor for Celland Neurobiology at the KIT, Germany. He received his Ph.D. in Biology in 1989 from the University of Kaiserslautern, Germany. As a postdoc he worked at the MPI in Tübingen and at the Salk Institute in San Diego. He was then a Research Associate and Assistant Professor at the University Konstanz. In 1998 he was awarded a Heisenberg Stipend from the DFG. From 2001-2004 he was a Professor for Neurobiology in Jena, and since 2004 he has been at the KIT. His research interests include nervous system development, cell mechanics, surface biofunctionalization, cell growth in

tailored 3D scaffolds, and the development of advanced light microscopy techniques.

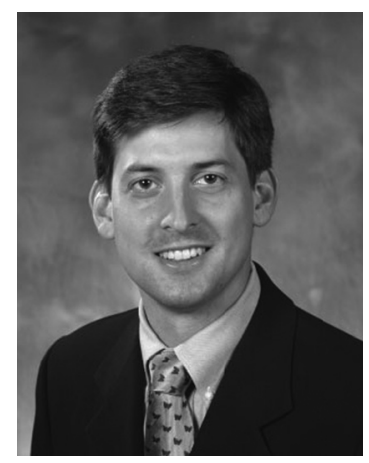

Jörg Lahann is an Associate Professor of Chemical Engineering at the University of Michigan as well as the Co-director of the Institute of Functional Interfaces at the Karlsruhe Institute of Technology (KIT). His research focuses on the interface between synthetic materials and biological systems. Jörg Lahann is a recipient of a 2006 DOD Idea award, the 2007 NSEF Award of the AICHE, and an NSF-CAREER award. He is a fellow of the American Institute of Medical and Biological Engineers, the author of more than 120 publications, and the inventor or co-inventor of more than 25 patents or patent applications.

to a host of biological applications, and the ease at which they can be modified, provides a large research space for probing cell-material interactions.

\subsection{Topography of Hard Materials}

Numerous metallic substrates have been utilized in the healthcare industry including stainless steel, platinum, titanium, and silicon. ${ }^{[43,44]}$ These materials have served as joint replacements, dental implants, and electrode materials for brain stimulation. For many of these applications, modification of the metallic surface is beneficial, often because of enhanced biomaterial-cell interactions. Techniques, such as micromachining, chemical etching, and photolithography have been employed to alter the surface topography. In particular, sandblasting and acid etching are commonly 

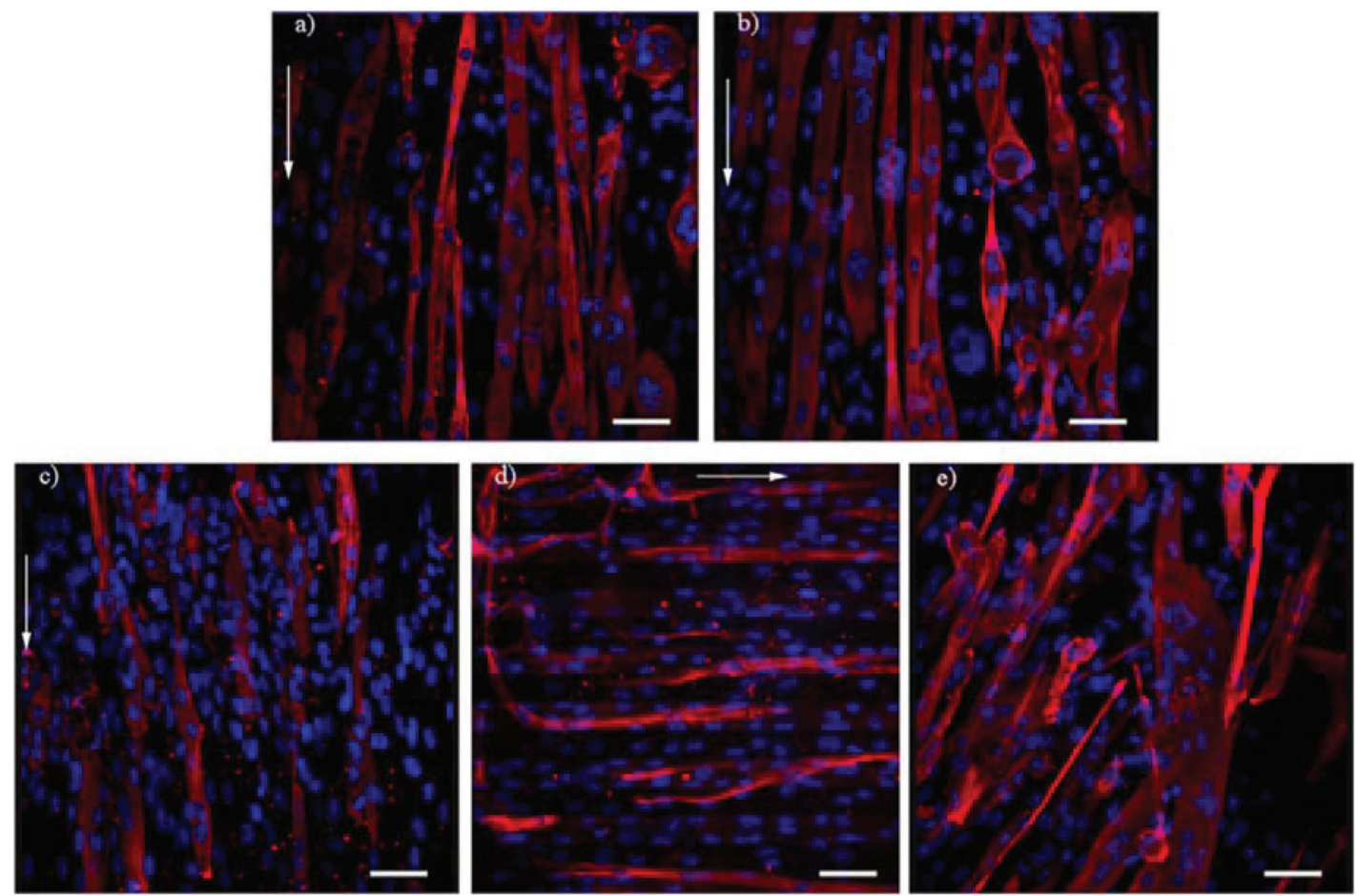

Figure 1. Immunofluorescence of C2C12 skeletal muscle cells on PLLA-TMC substrates at various groove depths and $25 \mu \mathrm{m}$ in width after 7 days of culture: a) $1 \mu \mathrm{m}$, b) $2.5 \mu \mathrm{m}$, c) $5 \mu \mathrm{m}$, and d) smooth surface, and e) staining: blue, nuclei; red, myosin. Arrow indicates groove direction. Scale bar $=100 \mu \mathrm{m}$. Reproduced with permission. ${ }^{[38]}$ Copyright 2010 Elsevier.

utilized to modify the roughness of implants. In vitro studies have indicated that roughness changes modulate adhesion, cytokine release, and gene expression of osteogenic cells. ${ }^{[45,46]}$

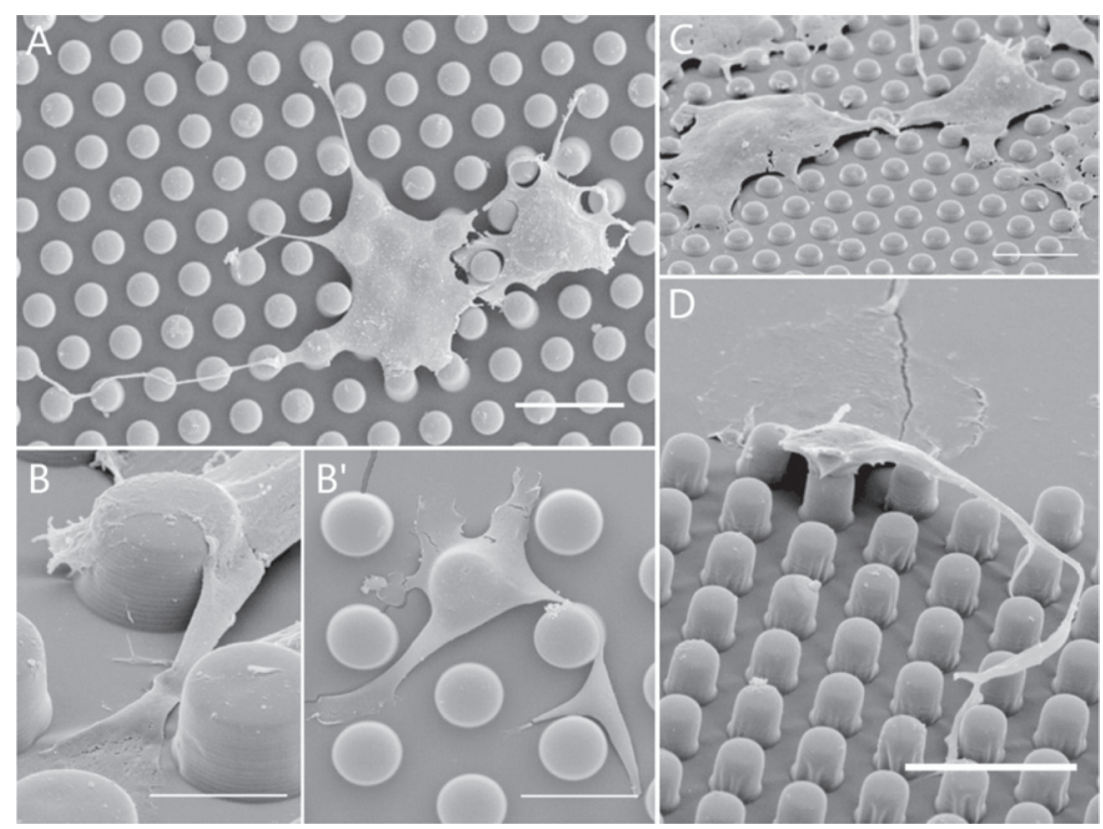

Figure 2. Scanning electron microscopy (SEM) images of fibroblast response to the height, diameter, and spacing of the pillars. A) Cells on pillars $(10 \mu \mathrm{m}$ height, $5 \mu \mathrm{m}$ diameter, $5 \mu \mathrm{m}$ spacing) and display projections; B/B') cells on top and between pillars. C) Cells on pillars ( $2 \mu \mathrm{m}$ height, $5 \mu \mathrm{m}$ diameter, $5 \mu \mathrm{m}$ spacing) have cell morphology similar to that on flat surfaces. D) Cells on pillars ( $6 \mu \mathrm{m}$ height, $5 \mu \mathrm{m}$ diameter, $5 \mu \mathrm{m}$ spacing) display large lamellopodia on flat portions and branched morphology on pillars. Scale bar $=20 \mu \mathrm{m}$. Reproduced with permission. ${ }^{[41]}$ Copyright 2009 Elsevier.
However, the cellular response to topographical changes on metallic materials is cell-type dependent.

Turner et al. used pillars and wells to influence astroglial cell behavior. ${ }^{[47]}$ Pillar and well arrays were fabricated by photolithographic and etching techniques. In this work, the surface topography consisted of pillars of varied width $(0.5-2 \mu \mathrm{m})$ and spacing (1-5 $\mu \mathrm{m})$ in addition to $1 \mu \mathrm{m}$ deep microwells with varied spacing $(0.5-2 \mu \mathrm{m})$ on silicon. As compared to smooth controls, $70 \%$ of LRM55 astroglial cells preferentially adhered to pillars, while there was no significant difference in cell adhesion onto welled structures. Actin and vinculin staining was used to explore microfilament and focal contacts of attached cells and results indicated that focal contacts occurred at the end of many actin bundles and were localized on the tops of the pillars. Irrespective of the interpillar spacing assessed in this work, astroglial cells only adhered to the tops of the pillars. This microstructuring could be beneficial in the design of neural prosthesis and for basic studies investigating cellular, growth, attachment, and morphology.

$\mathrm{Lu}$ et al. investigated micro- and nanostructured metal surfaces for coronary stents. In particular, the authors used lithography and titanium inductively 

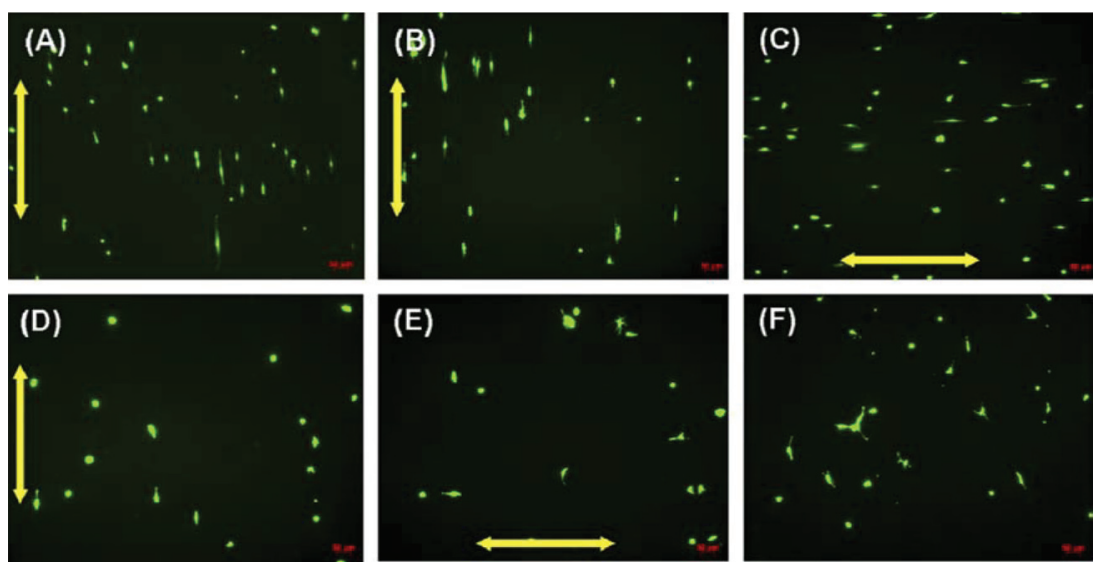

Figure 3. Density after 3 days of culture of rat aortic endothelial cells on patterned Ti substrates of A) $750 \mathrm{~nm}$, B) $1 \mu \mathrm{m}$, C) $5 \mu \mathrm{m}$, D) $75 \mu \mathrm{m}$, E) $100 \mu \mathrm{m}$, and F) randomly nanostructured Ti surfaces. Arrows indicate direction of groove alignment for patterned substrates. Scale bar $=$ $50 \mu \mathrm{m}$. Reproduced with permission. ${ }^{[48]}$ Copyright 2008 Elsevier.

coupled plasma deep etching to generate high-resolution topographical features in titanium and assessed the substrates in rat endothelial cell culture. ${ }^{[48]}$ The surface topography consisted of a periodic array of lines that varied in spacing from $750 \mathrm{~nm}$ to $100 \mu \mathrm{m}$ but maintained a constant width. Randomly structured titanium and smooth titanium served as controls and rat endothelial cell behavior was assessed as a function of line spacing. Nanostructured surfaces led to an enhancement in cell adhesion and growth, as compared to larger microstructured surfaces and controls (Figure 3). Additionally, cells aligned along the structure affording control over cell alignment similar to the alignment that occurs along the endothelium in vivo. Potential applications of this work include stents for cardiovascular repair and bone implants with enhanced osseointegration.

\subsection{Roughness}

Surface roughness relates to the texture of the uppermost layer of a material and is quantified by measuring the protrusions or depressions at the surface. Abundant evidence suggests that surface roughness plays an important role in manipulating cell behavior for implant biomaterials such as titanium, ceramics, stainless steel, and polymers. The roughness value $\left(R_{\mathrm{a}}\right)$, quantitatively depicts the degree of roughness for a given surface and is thus widely used to describe the surface of in vitro cell culture matrices. However, similar $R_{\text {a }}$ can result in different stimuli for the surrounding biological environments because surfaces may be covered with different nanoscopic topologies and patterns such as grafts, posts, grooves, and pits. ${ }^{[7,49]}$ Owing to recent advancements in nanofabrication, surface topologies can be controlled in the nanometer range, and well-controlled roughness with respect to $R_{\mathrm{a}}$, shape, and geometry can be produced. Methods for creating surface roughness include blasting, [50] electropolishing, ${ }^{51]}$ nanoparticle/fiber formation, ${ }^{[52]}$ chemical treatment, ${ }^{[53,54]}$ as well as nanofabrication technologies, such as photolithography, ${ }^{[55,56]}$ electron beam lithography, ${ }^{[5]}$ dip-pen nanolithography, ${ }^{[57]}$ imprint lithography, ${ }^{[58,59]}$ and colloidal lithography. ${ }^{[60]}$ Studies have revealed decreased proliferation and increased differentiation of osteoblasts with increased surface roughness. ${ }^{[61,62]}$ Moreover, surfaces with increased roughness showed suppressed proliferation and/or differentiation of leukocytes, keratinocytes, and monocytes. ${ }^{[49]}$

Similarly, it is found that a higher percentage of osteoblast cells attached to rougher surfaces, ${ }^{[63]}$ while in a separate study, evaluation of the attachment of gingival and periodontal ligament fibroblasts and epithelial cells was preferential on smooth surfaces. ${ }^{[64]}$ More specifically, human mesenchymal stem cells were stimulated by disordered nanotopography to produce bone mineral in vitro, without osteogenic supplements, and a distinct differentiation profile was displayed. ${ }^{[5]}$ In this section, we limit the scope of our discussions to surfaces that have roughness in anisotropy and surfaces with suppressed topographical stimuli, i.e., smooth surfaces, and will highlight the consequences of these stimuli on cell responses and functions for polymeric surfaces.

The roughness of polymer surfaces may be altered to influence the behavior of various cell types. ${ }^{[65,66]}$ It is often desirable to change the surface roughness of a material without changing its chemical composition. PDMS is a widely used biomaterial with tunable surface properties. The roughness of structured PDMS as well as epoxide-based photoresists SU-8 and 1002F were modified by Shadpour and colleagues by means of polishing with an alumina particle slurry. ${ }^{[67]}$ A roughening duration between $15-30 \mathrm{~s}$ was utilized and generated an average roughness $\left(R_{\mathrm{a}}\right)$ of approximately 7.7-19.8 nm for SU8 and 1002F resists. Although this represented an increase of four- to ninefold in surface roughness as compared to native surfaces, less than $1 \%$ of the structured features were damaged or destroyed. Post polishing, three diverse cell types, rat basophilic leukemia (RBL), HeLa, and 3 T3 fibroblasts, were seeded onto the roughened substrates. Cell adhesion and growth on the rough substrates was enhanced irrespective of the cell type. Moreover, roughening of the surface and stamp for microcontact printing, increased protein adsorption to the roughened surface by 20 -fold.

Poly-lactic-co-glycolic acid (PLGA) is another widely utilized polymeric biomaterial. This synthetic polymer has clinical applications in the replacement of diseased bladder tissue. ${ }^{68-70]}$ Clinical utility may be enhanced by eliminating the mismatch in surface properties between the smooth polymer surfaces and the rough surfaces of the native bladder. ${ }^{[71]}$ Therefore, altering the surface roughness of these materials has been pursued. Recently Chun et al. used chemical etching to increase the surface roughness of PLGA and poly(ether) urethane (PU) polymers. ${ }^{[72]}$ Etching resulted in a porous $\mathrm{PU}$ surface and a nanorough PLGA surface (Figure 4).

Human urothelial cells (HUCs) were seeded onto etched surfaces and the influence of surface roughness was assessed. 

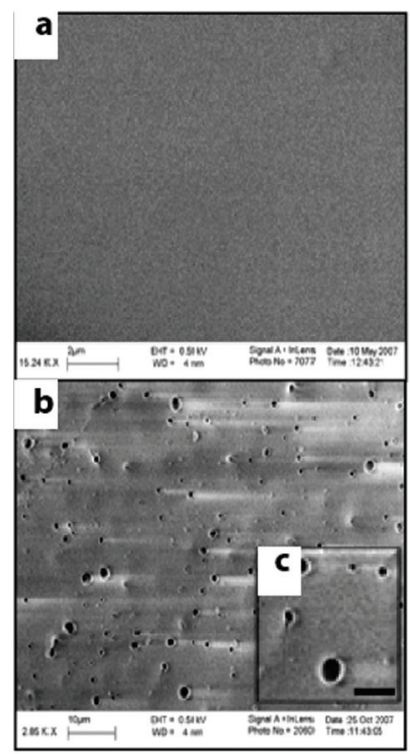
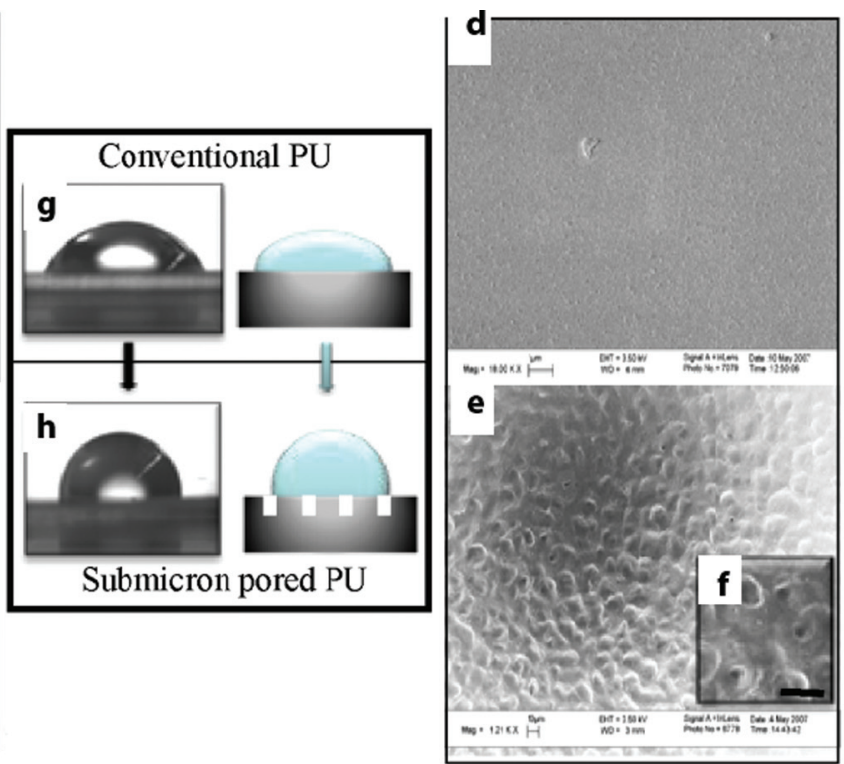

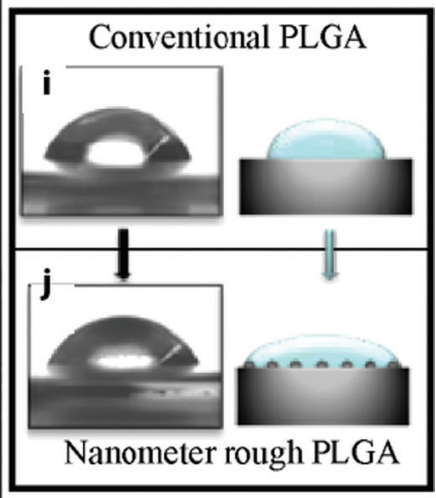

Figure 4. SEM images of polymer surfaces: a) untreated PU, b) porous PU, d) untreated PLGA, and e) nanometer-rough PLGA. The insets of b and e are magnifications of the porous PU (c) and nanometer-rough PLGA (f), respectively, with a $1 \mu$ m scale bar. Water-contact angles of treated polymer surface: h) PU and j) PLGA. Reproduced with permission. ${ }^{[72]}$ Copyright 2009 Insitute of Physics.

HUCs were found to adhere more readily to roughened substrates and nanometer rough PLGA resulted in the greatest cell adhesion. ${ }^{[72]}$

Surface topographies may also be generated by interfacial polymer demixing. The foundation of this method is the phase separation of polymer blends upon spin-casting onto a substrate. ${ }^{[73]}$ Adjusting the polymer ratio and concentration affords some control over feature size and shape. ${ }^{[74]}$ For example, Lim et al., produced nanotopographies to investigate human foetal osteoblastic (hFOB) cell response to surface roughness using polymer demixing of polystyrene (PS)/polybromostyrene (PBrS). ${ }^{[75]}$ In this work, variable polymer concentrations were utilized to fabricate three feature heights, 11 , 38 , and $85 \mathrm{~nm}$. Cell seeding occurred on the substrates, and cell behavior in terms of adhesion and morphology was evaluated. The shortest nanotopography yielded enhanced cell spreading and size as compared to taller topographies and planar PS and $\mathrm{PBrS}$ substrates. Focal adhesions and actin stress fibers were more readily apparent on the $11 \mathrm{~nm}$ feature height (Figure 5). Additionally, the $11 \mathrm{~nm}$ topographies influenced osteoblast phenotype, as cells cultured on these topographies had elevated levels of alkaline phosphatase, an early marker of bone differentiation. In general, cell adhesion and spreading were more favorable, when the height of the nanotopographies was reduced. An inherent limitation of this technique is the convolution of chemistry with changes in feature height as both changes could lead to differences in surface roughness.

\section{Elasticity}

The functional importance of elasticity has been increasingly revealed in the past decade. Cells in multicellular organisms live in an environment with gradations of deformable physical properties which increase, including brain tissue, muscle, cartilage, and bone. ${ }^{[14]}$ Cells may also have different rigidities depending on their tissue origin. ${ }^{[76]}$ Because of its fundamental role in many aspects of cell functions such as adhesion, ${ }^{[77]}$ polarization and migration, ${ }^{[78]}$ proliferation and differentiation, ${ }^{[14]}$ the impact of substrate elasticity and how cells process this signal has been studied intensively. Initial investigations were carried out on diverse hydrogels such as collagen, ${ }^{[79,80]}$ fibrin, ${ }^{[81]}$ agarose, ${ }^{[82]}$ alginate ${ }^{[83]}$ or polyacrylamide, ${ }^{[77,84]}$ hyaluronic acid, ${ }^{[85,86]}$ Matrigel, ${ }^{[87]}$ and tumor models in mice. ${ }^{[88]}$ These studies delivered important knowledge about the way cells react to environmental elasticity ${ }^{[1]}$ and provide guidance on how to modify and optimize materials for regenerative medicine. ${ }^{\left[{ }^{89}\right]}$ Commonly utilized gels are random composites without structural or dimensional definition. For example, variations in the thickness of a thixotropic gel can control proliferation and differentiation of mesenchymal stem cells (MSCs) in 3D substrates. ${ }^{[90]}$ Still, these undefined gels may be sufficient for qualitative studies on the role of elasticity on cell behavior. However for quantitative studies such as those concerning cell mechanics, geometrically defined substrates are required to provide reference points for calculation and modeling. For this approach, other materials and modifications of the existing gels will need to be introduced. ${ }^{[91]}$

In this section, we focus on methods used to prepare elastic cell culture substrates with different stiffness and the specific modification of these substrates for various topics (as shown in Table 1). We will describe new developments in the materials and fabrication methods of these substrates and analyze the major achievements in terms of cell biology based on investigations using such substrates.

\subsection{Strategies to Tune the Substrate Elasticity}

The basic principle of tuning substrate elasticity relies on modifying the crosslinking density of a polymer. ${ }^{[104]}$ For 


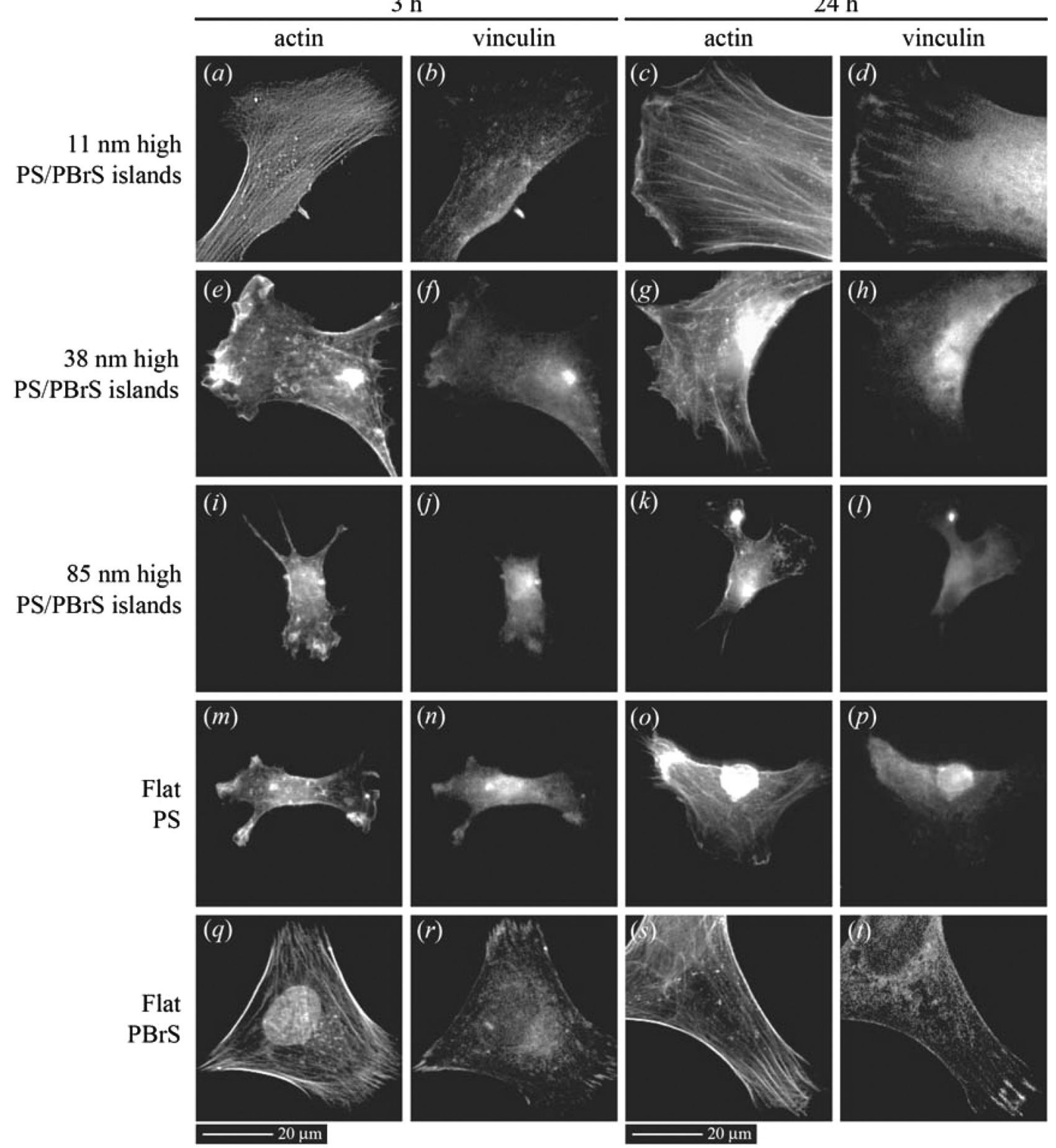

Figure 5. Actin and vinculin staining of hFOB cells cultured on control and nanotopographies for 3 and $24 \mathrm{~h}$ time periods. Cells on $11 \mathrm{~nm}$ surface features $(c, d)$ had more diffused actin and vinculin reactivities than the highest surface features $(k, l)$. Reproduced with permission. ${ }^{[75]}$ Copyright 2005 Royal Society of Chemistry.

collagen gels, the gelation kinetics, as well as fiber diameters and porosity, can vary significantly with collagen concentration. In contrast, hyaluronic acid (HA) typically does not provide adequate rigidity for in vitro cell culture. To circumvent this limitation, different methods have been developed for crosslinking, including chemical crosslinking, photocrosslinking, and combination with other hydrogels or biomacromolecules, such as DNA. ${ }^{[105]}$
Gelation of HA occurs after modification through thiolation $^{[86]}$ or acrylation. ${ }^{[106]}$ Thiolated HA needs a bifunctional electrophilic crosslinker, poly(ethylene glycol)-diacrylate (PEG-DA), to polymerize. The stiffness of the gel will be defined by the concentration of the thiolated HA. ${ }^{\left[{ }^{86}\right]}$ A concentration of $0.5 \%(\mathrm{w} / \mathrm{v})$ resulted in optimal neurite outgrowth in vivo. In comparison to a fibrin control, the HA gel promoted stronger long-term neurite outgrowth, with growth occurring until $192 \mathrm{~h}$ 
Table 1. Examples of elastic substrates with different dimensionality.

\begin{tabular}{|c|c|c|c|c|c|c|c|}
\hline \multirow[t]{2}{*}{ Dimension } & \multirow[t]{2}{*}{ Method } & \multirow[t]{2}{*}{ Material } & \multirow{2}{*}{$\begin{array}{l}\text { Elasticity (Young's } \\
\text { modulus) }\end{array}$} & \multicolumn{3}{|c|}{ Biological application } & \multirow[t]{2}{*}{ Ref. } \\
\hline & & & & $\begin{array}{l}\text { Surface } \\
\text { treatment }\end{array}$ & Cell type & Effect & \\
\hline Flat & - & $\begin{array}{l}\text { Silicone rubber } \\
\text { (PDMS) }\end{array}$ & - & - & $\begin{array}{l}\text { Heart fibroblast, liver paren- } \\
\text { chymal cells, pigmented } \\
\text { retina cells }\end{array}$ & All cell types can wrinkle the substrate. & [92] \\
\hline Flat & $\begin{array}{l}\text { Soft lithography, } \\
\text { direct e-beam } \\
\text { writing, microcon- } \\
\text { tact printing }\end{array}$ & PDMS, PMMA & $\sim 15 \mathrm{kPa}$ & Fibronectin & $\begin{array}{l}\text { Human foreskin fibroblast, } \\
\text { rat cardiomyocyte and } \\
\text { cardiac fibroblast }\end{array}$ & $\begin{array}{l}\text { Local forces show a correlation to the } \\
\text { orientation and the size of the focal } \\
\text { adhesion. The stress is constant at } \\
\qquad 5.5 \pm 2 \mathrm{nN} \mathrm{\mu m}^{-2} \text {. }\end{array}$ & [93] \\
\hline Flat & $\begin{array}{l}\text { Replica molding } \\
\text { with embedding } \\
\text { microbeads }\end{array}$ & PDMS & $\sim 16-38 \mathrm{kPa}$ & Fibronectin & Rat cardiac fibroblast & $\begin{array}{l}\text { Explicit equations for mechanical } \\
\text { response of elastic layer were derived, } \\
\text { which allows highly accurate force } \\
\text { measurement by eukaryotic cells. }\end{array}$ & [94] \\
\hline Flat & - & $\begin{array}{c}\text { Poly } \\
\text { (acrylamide) }\end{array}$ & $\sim 5-8.5 \mathrm{kPa}$ & Collagen type I & $\begin{array}{l}\text { Dictyostelium } \\
\text { discoideum }\end{array}$ & $\begin{array}{l}\text { Separate friction forces in the tip and } \\
\text { tail of the slug and its magnitude } \\
\text { decreases with the slug velocity. }\end{array}$ & [95] \\
\hline Topo & Replica molding & PDMS & $\begin{array}{l}2.5 \mathrm{MPa}, 1600-2.7 \\
\mathrm{nN} / \mu \mathrm{m} \text { depending } \\
\text { on diameter and } \\
\text { height of the posts }\end{array}$ & $\begin{array}{l}\text { Fibronectin, } \\
\text { collagen IV }\end{array}$ & $\begin{array}{l}\text { Bovine pulmonary artery } \\
\text { smooth muscle cells } \\
\text { (BPASMC), NIH3T3 mouse } \\
\text { fibroblasts, bovine pulmo- } \\
\text { nary artery endothelial cells } \\
\text { (BPAEC), }{ }^{[96]} \text { Madin-Darby } \\
\text { canine kidney epithelial } \\
\text { cells (MDCK) }{ }^{[97]}\end{array}$ & $\begin{array}{l}\text { Positive correlation between force and } \\
\text { contact size only by contacts bigger } \\
\text { than } 1 \mu \mathrm{m} \text {. Spreading is important for } \\
\text { force generation. RhoA can rescue } \\
\text { contractility by unspread cells; }{ }^{[96]} \\
\text { Maximum intensity of the force } \\
\text { localized at the periphery of the } \\
\text { epithelia. }\end{array}$ & {$[96,97]$} \\
\hline Topo & Replica molding & Poly (acrylamide) & - & $\begin{array}{l}\text { poly(L-lysine) } \\
\quad \text { (PLL) }\end{array}$ & $\begin{array}{l}\text { Spinal commissural } \\
\text { neuron }(\mathrm{SCN})\end{array}$ & $\begin{array}{l}\text { SCN growth cones applied ranged from } 2 \\
\text { to } 37 \mathrm{pN} \text { with the average at } 9 \mathrm{pN}\end{array}$ & [98] \\
\hline Topo & Replica molding & PDMS & $\begin{array}{l}\text { Spring constant, } \\
k=32 \mathrm{nN} / \mu \mathrm{m}\end{array}$ & Fibronectin & NIH3T3 & $\begin{array}{l}\text { External applied forces induced local } \\
\text { enhancement of focal adhesions. A } \\
\text { sudden loss or a gradual decay in contrac- } \\
\text { tility was recorded after stimulation. }\end{array}$ & [2] \\
\hline $3 \mathrm{D}$ & $\begin{array}{l}\text { Two-photon direct } \\
\text { laser writing }\end{array}$ & Ormocomp & $800 \mathrm{MPa}$ & Fibronectin & $\begin{array}{l}\text { Primary chicken } \\
\text { cardiomyocytes }\end{array}$ & $\begin{array}{l}\text { First tailored elastic 3D substrate for cell } \\
\text { culture study, which theoretically could } \\
\text { measure cell applied forces of } 20 \mathrm{nN} \text {. }\end{array}$ & [99] \\
\hline $3 \mathrm{D}$ & $\begin{array}{l}\text { Microfabrica- } \\
\text { tion and soft } \\
\text { lithography }\end{array}$ & PDMS & - & - & $\begin{array}{l}\text { Connect tissue } \\
\text { progenitor cells }\end{array}$ & $\begin{array}{l}\text { Increased proliferation and expression } \\
\text { of alkaline phosphatase, but no effect } \\
\text { on expression of osteocalcin. }\end{array}$ & [100] \\
\hline $3 \mathrm{D}$ & $\begin{array}{l}\text { Two-photon } \\
\text { laser scanning } \\
\text { photolithography }\end{array}$ & PEG & - & RGD & Human dermal fibroblast & $\begin{array}{l}\text { The precisely } 3 D \text { distribution of RGD } \\
\text { peptides guided cell migration in the } \\
\text { collagenase-sensitive hydrogels. }\end{array}$ & [101] \\
\hline Gradient & Photolithograhy & $\begin{array}{l}\text { Styrenated } \\
\text { gelatin }\end{array}$ & $10-400 \mathrm{kPa}$ & - & 3T3-Swiss albino & $\begin{array}{l}\text { Two critical criteria of the elasticity jump } \\
\text { and the absolute elasticity to induce } \\
\text { mechanotaxis were identified: } 1 \text { ) a high } \\
\text { elasticity ratio between the hard and soft } \\
\text { regions, and 2) elasticity of the softer } \\
\text { region to provide medium motility. }\end{array}$ & [102] \\
\hline Gradient & $\begin{array}{l}\text { Compressing of } \\
\text { wedge-shaped } \\
\text { collagen matrix }\end{array}$ & Collagen I & $1000-2300 \mathrm{kPa}$ & Collagen I & Human dermal fibroblast & $\begin{array}{l}\text { Cell accumulation prefers the stiff } \\
\text { part of the substrate, and durotactic } \\
\text { migration was observed significantly } \\
\text { after } 6 \text { days. }\end{array}$ & [103] \\
\hline
\end{tabular}

as compared to $60 \mathrm{~h}$ for the control. However, placing this gel on the site of a complete thoracic spinal cord transection in rats did not aid in injury recovery. Kim et al. modified HA by acrylation and used an matrix metalloproteinase (MMP) degradable peptide as a crosslinker and found that mesenchymal stem cell spreading was enhanced as compared to hydrogels without MMP ${ }^{[106]}$ Recently, thiol-ene photopolymerization was utilized to create a PEG hydrogel that incorporated an MMP degradable peptide. This peptide-functionalized, cell-degradable hydrogel encapsulated mesenchymal stem cells and facilitated directed cell differentiation into osteogenic, chondrogenic, and adipogenic lineages with specific differentiation markers being more highly expressed on these hydrogels than hydrogels that are not cell degradable. ${ }^{[107]}$ 
The control and verification of the concentration of the gel precursor is the earliest and simplest way to tune the substrate stiffness. Solely by changing the concentration of collagen protein in the solution from 0.4 to $2.0 \mathrm{mg} / \mathrm{mL}$, the collagen gel stiffness can be varied from 2.2 to about $17.0 \mathrm{~Pa} .{ }^{[108]}$ However, this stiffness is still too soft to simulate brain tissue, which has an elasticity from $\sim 100$ to $\sim 1000 \mathrm{~Pa}^{\left[{ }^{[109]}\right.}$ In order to increase substrate stiffness, Ulrich et al. combined collagen with agarose gel and altered the gel stiffness by changing the concentration of agarose. Increasing the concentration of agarose from $0 \%$ to $1 \%$ leads to an increase of substrate stiffness from $2 \mathrm{~Pa}$ to $1 \mathrm{kPa} \cdot{ }^{[110]}$ Other methods to improve the mechanical strength of collagen gel including enzymatic crosslinking with transglutaminase ${ }^{[111]}$ or chemical crosslinking with glutaraldehyde ${ }^{[12]}$ have been developed. Substrate elasticity may also be modulated via controlled erosion. Tibbitt and colleagues used two-photon induced erosion to alter the elasticity of a PEG hydrogel in situ to investigate the influence of dynamic elasticity changes on the adhesion of mesenchymal stem cells. ${ }^{[113]}$

A widely used synthetic hydrogel is polyacrylamide (PAA), which has acrylamide (AA) as base prepolymer and $N, N$-methylene-bis-acrylamide (BIS) as crosslinker. In this case, simple variation of both AA and BIS can change the stiffness of substrates. The influence of the stiffness of polyacrylamide on cell behavior was introduced by Pelham and Wang. ${ }^{[77,114]}$ By varying the concentration of BIS crosslinker, the stiffness of the hydrogel could be adjusted from 0.1 to $80 \mathrm{kPa},{ }^{[115-117]}$ which covers nearly the whole elasticity range of natural soft tissue. Due to the fact that PAA is not a natural material and does not support cell adhesion, PAA gels for cell studies must, in contrast to collagen and hyaluronic acid, be functionalized, mostly by covalent binding of ECM proteins, such as collagen, laminin, fibronectin, or RGD peptide ( RGD = arginine-glycine-aspartic acid), through the photoactivated $N$-succinimidyl-6-(4'-azido-2'-nitrophenylamino) hexanoate (SANPAH)-linker.

Using PAA substrates with stiffness of $\sim 0.1-40 \mathrm{kPa}$, Engler et al. varied the surface density of collagen ligands and found the spreading of smooth muscle cells (SMCs) increased with the substrate stiffness. ${ }^{[115]}$ Cells achieved maximal size at intermediate ligand density and with increasing collagen density, cells became smaller again. Cellular preference to adhere and spread better on stiffer substrates has been described as "durotaxis"[118] and SMCs showed the same character as other anchorage-dependent cell types. Conversely, some cancer cells do not show this preference. Tilghman et al. cultivated cancer cells derived from different tissue origin on substrates with systematically varied elasticity from $\sim 0.15$ to $\sim 9.6 \mathrm{kPa}$ in a soft-plate multiwell assay. ${ }^{[84]}$ Depending on proliferation and cellular phenotype, the authors found that cells could be distinguished by their dependency on substrate rigidity. The stiffness-dependent growth profile showed no correlation to the tissue of origin, or whether the cells were originally cultured from the primary tumor or from a metastatic lesion.

By combining different concentrations of AA and BIS, Saha et al. prepared substrates with rigidity from $10 \mathrm{~Pa}$ to $10 \mathrm{kPa},{ }^{[119]}$ which are relevant to neural tissue with an elastic modulus of $100-1000 \mathrm{~Pa}$. Cultivation of rat adult neural stem cells (aNSC9) on these substrates showed that optimal neuronal differentiation was observed near the mechanical properties of native brain tissue. Engler et al. found the stiffness of the substrates alone influenced the lineage of differentiation of mesenchymal stem cells (MSC). ${ }^{[14]}$ They cultivated MSCs on PAA substrates with rigidities covering the range from soft brain tissue to hard cartilage using constant serum conditions. The expression of specific tissue markers varied on substrates of different stiffness, and this expression was correlated to the rigidity of the substrate, which was similar to that of natural tissues. In contrast, Rowlands et al. showed that substrate stiffness alone does not direct, but rather modifies, stem cell lineage specification. ${ }^{[116]}$ In this work, cells were cultivated on PAA gels with a stiffness of $\sim 0.7-80 \mathrm{kPa}$, which were coated with different ECM molecules by a photoactivated cross linker. Significant osteogenic differentiation was observed by $80 \mathrm{kPa}$, while myogenic differentiation on all gels was observed for a stiffness greater than $9 \mathrm{kPa}$. Cellular differentiation was modulated by the type ECM proteins used for coating.

PDMS is most commonly used in soft lithography and was first adapted by Whitesides' group. ${ }^{[12]}$ PDMS has excellent optical properties due to its colorless and transparent appearance. Importantly, the stiffness of the resultant PDMS can be adjusted by altering the amount of the individual mixing components, the base substance and the curing agent. The stiffness of the substrate decreases from $2 \mathrm{MPa}$ at a ratio of 10:1 between base prepolymer and the curing agent to $0.05 \mathrm{MPa}$ at a ratio of 50:1. ${ }^{[120]}$ The stiffness of PDMS is greater than other elastic materials, such as collagen and PAA, which only have rigidity on the order of hundreds of kilopascals. PDMS could be used to simulate much stiffer tissues like blood vessel walls or cartilage. Because a ratio of basic prepolymer to curing agent lower than 10:1 does not increase the substrate stiffness and a ratio of more than $55: 1$ is difficult to handle, the most used ratio lies between 10:1 and 55:1. ${ }^{[94]}$ The resulting PDMS substrate can be planar, topological, ${ }^{[96]}$ or even three dimensional. ${ }^{[99]}$ These elastic substrates enable the quantitative visualization of the surface deformation by cell applied force, ${ }^{[93]}$ i.e., the measurement of the force applied by cells through a single focal contact. Using substrates with elastic needles embedding cobalt nanowires, not only can the force applied by cells be measured, but cells can also be manipulated with external force, ${ }^{[2]}$ such as in stretching experiments. ${ }^{[121]}$ These artificial substrates therefore enable both the quantification of the mechanical properties of the cell and provide the opportunity to control or manipulate cell behavior.

\subsubsection{Controlled Photo-activation and Photodegradation}

Photocrosslinking has been frequently used to drive polymerization of different elastomers such as collagen or PAA. Prepolymers are mostly modified to be photoactive or photosensitive through the use of an appropriate crosslinker. The substrate elasticity can be tuned by controlling the intensity ${ }^{[122]}$ or the time ${ }^{[123]}$ of irradiation. If a constant intensity and irradiation time are used, the stiffness of the substrates may also be varied by changing the concentration of the photoinitiators.

Polyvinyl alcohol (PVA) hydrogels were modified to be photo-active by reaction with methacrylamidacetaldehyde 
dimethyl acetal. The modified PVA can be polymerized by long-wavelength UV light, and hydrogels with different stiffness could be manufactured by varying the concentration of PVA monomer. ${ }^{[124]}$ Another option for changing the stiffness of the substrates concerns controlling the extent of modification of the PVA monomer. Smaller modifications result in a weaker polymerization and thereby a softer substrate. By augmenting these various parameters, it is possible to prepare substrates with stiffness ranging 50-850 kPa. After functionalization with RGD peptide, the hydrogel was found to support the attachment and spreading of fibroblasts. ${ }^{[124]}$

\subsubsection{Varying Size and Valency of the Prepolymer}

The size of the prepolymer is sometimes important for determining the stiffness of substrates. ${ }^{[124]}$ The crosslinking site does not increase with the molecular weight of the prepolymer, which means that the length of the molecular chain after polymerization will input flexibility, and conversely, stiffness. De Forest et al. used this principle to vary the rigidity of substrates by controlling the size of prepolymers for polymerization using click chemistry. ${ }^{[125]}$ They used a four-arm PEG tetra-azide and a bis(cyclooctyne)-peptide (Figure 6). The size of the PEG arm was varied, and it determined the rigidity of the substrates, which was in the range of 1000-6000 Pa. Using free valences in the polymer, a chemical gradient for cell adhesion could be achieved by light-driven thiol-ene chemistry. Because both reactions occur in aqueous conditions and in the presence of cells, this material ultimately enables independent tuning of biochemical and biomechanical properties of the biomaterial network. Crowe-Willoughby et al. changed both the number of reactive vinyl groups in poly(vinylmethylsiloxane) (PVMS) and the size and number of hydride-terminated PDMS to manufacture PDMS-PVMS copolymer with different elasticity. ${ }^{[122]}$ By changing the PVMS number from 11 to 300 and using a constant degree of PDMS linker of 15 , the substrate stiffness was varied from 20 to $400 \mathrm{kPa}$. This work may be utilized to enhance understanding of cell behaviors (growth, proliferation, migration, etc.) on biomaterials with various stiffness properties.

\subsubsection{Physical Variation of the Substrate Stiffness}

Physical adjustment of the substrate elasticity is a strategy, where dimensions of the substrate, such as length, height and thickness, and distance are changed to affect either local or general stiffness of the substrate. This strategy is mostly used in substrates consisting of a bed of micropillars. Ghibaudo et al. changed the spring constant of single pillars by varying the length and diameter of the pillars, ${ }^{[126]}$ while Mussig et al. modified the general elasticity of pillar substrates by changing the distances between the pillars. ${ }^{[127]}$ Other researchers could prepare anisotropic substrates with asymmetrical distribution of elasticity in different directions by fabricating substrates consisting of pillars with oval cross-sections. ${ }^{[78,96]}$

Kocgozlu et al. used another material combination, polyelectrolyte multilayer (PEM), which consists of PLL/HA gels capped on top with poly(styrene) sulfonate/polyallylamine hydrochloride (PSS/PAH) multilayers. ${ }^{\left[{ }^{[5]}\right.}$ The PLL/HA gel is a viscous liquid with a stiffness near zero and is unfavorable for cell adhesion. In contrast, the PSS/PAH is stiff with stiffness in the gigapascal range, and it supports cell adhesion and proliferation. ${ }^{[128]}$ A multilayer with PLL/HA as a base and PSS/PAH as a cap results in an elastic substrate that supports cell growth.
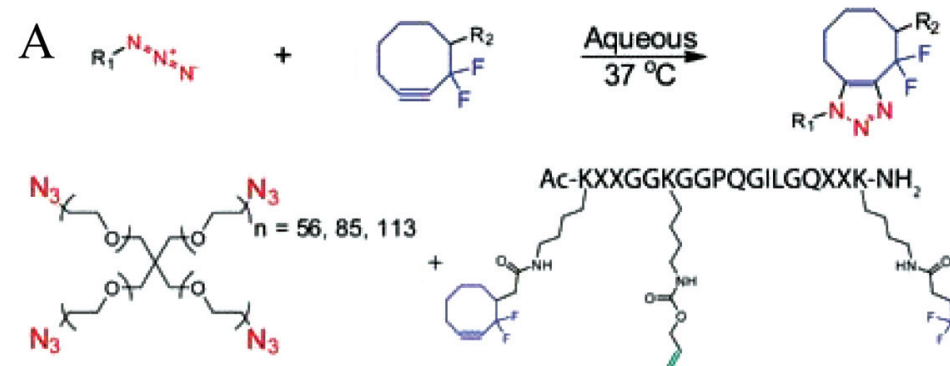

C-KXXGGKGGPQGILGQXXK-NH
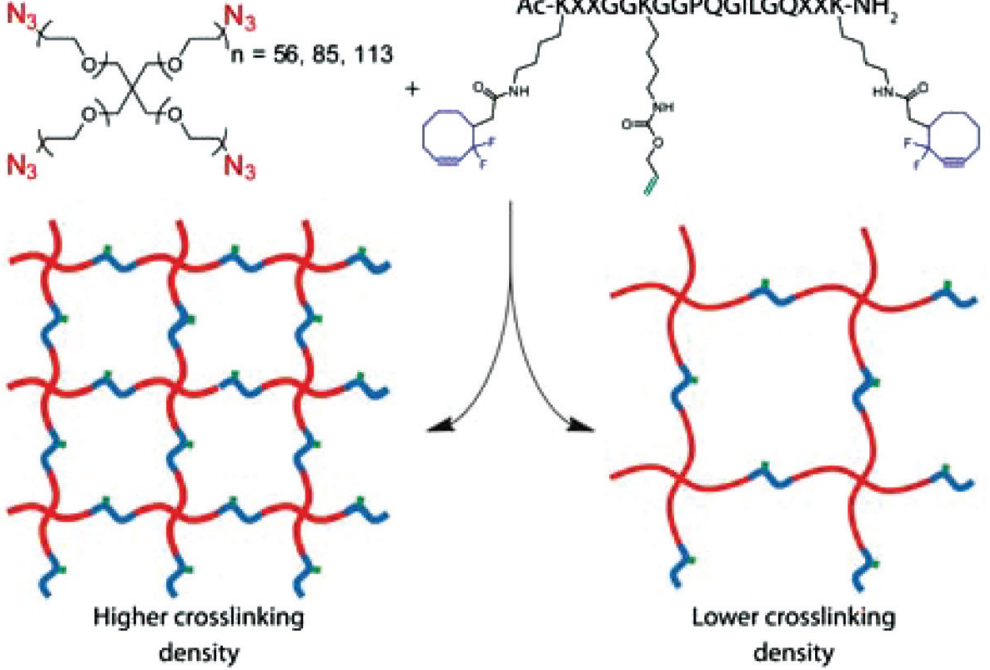

B
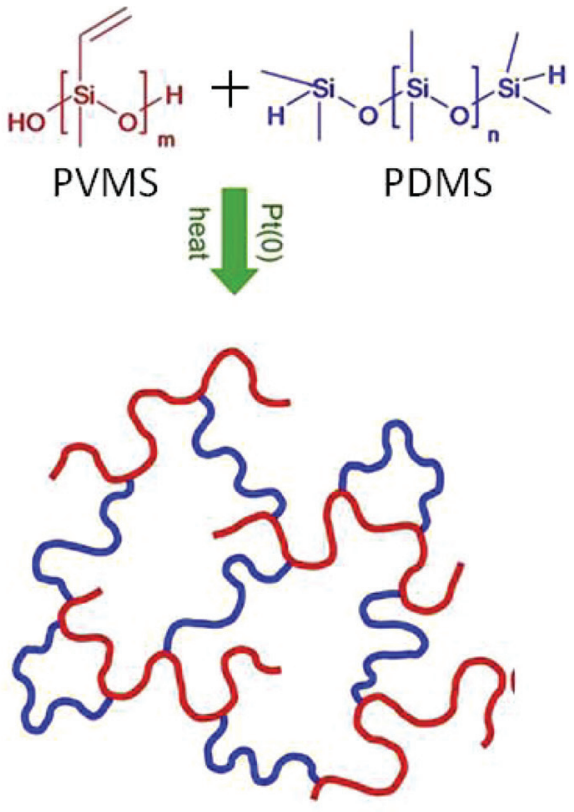

Figure 6. Controlling elasticity by changing the size (a) and valence (b) of the prepolymer. A) PEG-tetraazide reacts with bis(cyclooctyne)-peptide by click chemistry and builds a crosslinked gel, whose density is controlled by the size of the PEG backbone. Reproduced with permission. ${ }^{[125]}$ Copyright 2010 Royal Society of Chemistry. B) Schematic of PVMS/PDMS crosslinking mechanism. The amount and molecular weight of the hydrideterminated PDMS as well as the number of vinyl groups targeted for the cross-coupling reaction determine the degree of crosslinking. Reproduced with permission. ${ }^{[122]}$ Copyright 2010 Elsevier. 
With an increasing number of PSS/PAH layers, the stiffness of the substrates increases from 0 to $500 \mathrm{kPa}$. This substrate preparation strategy is generally the same as silicone rubber on liquid phase used by Harris et al. ${ }^{[92]}$ Only the stiffness of the substrate here can be better controlled by varying the number of PSS/PAH layers. In marsupial kidney epithelial cells (PtK2), DNA replication becomes efficient at stiffnesses above $200 \mathrm{kPa}$ while transcription already occurs above $50 \mathrm{kPa}$.

\subsection{Microstructured Substrates}

Elastic substrates are widely utilized to study a range of cellular responses. These substrates could be planar, where cells can only adhere and spread on the surface of the substrates, or they could be topographical or 3D and support cell adhesion in more than one direction. Dimensionality is increasingly recognized as being important for cell behavior. In fact, cells in organisms always live in a more or less $3 \mathrm{D}$ environment, and in vitro studies should simulate the in vivo situation as much as possible. Most investigations on $3 \mathrm{D}$ culture are carried out in different kinds of hydrogels, where cells are embedded in a matrix of collagen, matrigel, or other proteins or polymers. However, these substrates are not suitable for quantifying intracellular mechanics due to their structurally undefined surface character. To address this problem, different surface modification strategies of such substrates were devised. In particular, patterns are introduced on/in the surface of the planar substrates which can be deflected by cell applied forces when cells are cultivated on these substrates. By defining the elastic modulus of the substrates, the applied force or even the force of a single focal contact can be calculated by measuring the deflection of the substrates pattern. Different strategies were applied to bring the indicator into the substrate for quantifying the deformation of the substrate.

\subsubsection{Randomly Embedded Microbeads}

In tracking the deformation of substrates, it is important to define a visible reference point. Initially, reference markers were integrated by mixing small beads, with or without fluorescent label, in micro- or sub-micrometer scale, on/into the elastic substrates. These beads were added into the precursor mixture of the elastomer before polymerization. Either by gravitational or centrifugal force, the beads were aligned at the bottom of the mixture. A backbone material, mostly glass cover slips, was put on the mixture and a defined thickness was

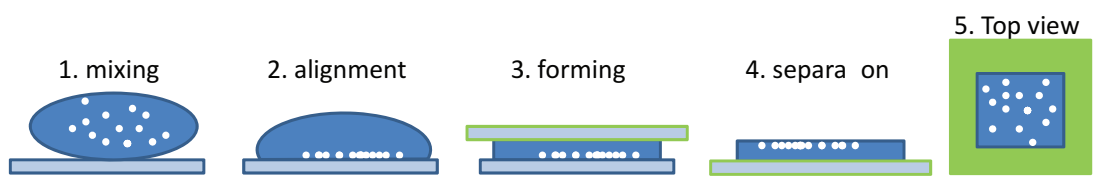

Figure 7. Schematic of the process of embedding microbeads in elastomers. 1) Microbeads are mixed in the prepolymer and put on the surface of a treated support, from which the elastomer should be easily separated. 2) Beads align at the bottom of the mixture. 3) A second treated glass slide to make the elastomer bind better covers the fluidics, and a spacer should be used to ensure a controlled thickness of the elastomer. 4) After separation of the elastomer from the support, the beads are found on top of the elastomer. 5) Top view shows the irregular distribution of the beads. achieved by using a spacer. After separation of the polymerized elastomer, a flexible substrate with embedded microbeads is ready for cell experiments (Figure 7). This approach enabled simple methods of tracking the substrate deformation without changing the mechanical properties of the substrate.

This method was used by Munevar et al., who prepared PAA substrates with randomly embedded fluorescent latex beads with diameters of $200 \mathrm{~nm} \cdot{ }^{[129]} \mathrm{In}$ order to ensure controlled cell adhesion on the surface, the substrates were functionalized by covalent grafting of collagen I via a photo-activated linker. During cell cultivation and time-lapse imaging, the dislocation of single beads could be followed and the cell applied force could be calculated according to the distance of the dislocation on the basis of calibrated mechanical properties of the substrates. This method was described as traction force microscopy because it measured the cell applied traction force to the underlying substrates. For 3T3 cells, almost all of the force for forward cell locomotion came from the lamellipodium, which is mechanically distinct from the cell body. However, the beads were randomly distributed in these substrates, and the dislocation has to be followed by live cell imaging making the calculation of the cell mechanics more difficult and less precise.

The elasticity of PAA gels can be easily modified through variation of the BIS concentration and traction force microscopy was widely used to study the influence of substrates stiffness and to measure the cell applied force simultaneously. Using $40 \mathrm{~nm}$ fluorescent beads embedded in PAA substrates with a stiffness between 0.6 and $2.8 \mathrm{kPa}$, Aratyn-Schaus and Gardel found the myosin II dependent slip of focal adhesions (FA) by human osteosarcoma cells is modulated by the elasticity of the substrates. ${ }^{[130]}$ This method was not only used to study fibroblasts, but also other migrating cells such as neutrophils ${ }^{[131]}$ or Dictyostelium. ${ }^{[95]}$ The adhesion and chemotaxis of neutrophils depends on substrate mechanics. Neutrophils generate higher traction forces on stiffer substrates without change in migration speed. Using these substrates Rieu et al. could clearly distinguish forces in the tip and the tail of migrating Dictyostelium slugs. The traction forces mostly localized in the prespore region and were decreasing with slug velocity.

Bead embedding is not limited to PAA gels and could theoretically be used in all types of elastic substrates which are prepared from a fluidic pre-stage. Lee et al. embedded latex beads of $1 \mu \mathrm{m}$ in diameter under the surface of PDMS substrates, which were crosslinked by electrical treatment. ${ }^{[132]}$ Merkel et al. used PDMS as basic material to prepare thin-film substrates with a thickness of 5-10 $\mu \mathrm{m}$, wherein FluroBeads of $100 \mathrm{~nm}$ diameter were embedded. ${ }^{[94]}$ They investigated rat cardiac fibroblasts and derived explicit equations for the mechanical response of the substrate to point forces.

\subsubsection{Micropatterned Structures by Replica Molding}

The embedding of microbeads as markers enables the quantification of cell mechanics on elastic substrates. However, the 
distribution of the beads is always random and tracking of individual beads is inconvenient and is only possible through the use of complicated algorithms. An integrated visible pattern in the substrates should overcome this problem. Balaban et al. prepared elastic PDMS substrates with visible micropatterns using two different strategies based on replica molding. ${ }^{[93]}$ First, they used a minimal topography, positive (micropillars) or negative (microwells), which could be distinguished using phase-contrast microscopy as a reference. It is known that topography and nanoscale roughness also affect cell behavior. If topography is to be used as a marker, it has to be determined that it is not relevant to the behavior of the investigated cell. The preparation of such substrates is based on a negative silicon mold, which is manufactured through various photolithographic steps. Due to the limitation of phase-contrast microscopy, the smallest distinguishable distance between such microtopography is limited. The same group developed another method to pattern substrates in the same way, where they used GaAs as a base for preparing the mold. The photoresist was coated on GaAs and photopatterned as well. After curing of the elastomer in the mold, the resist was separated from the GaAs base and carried to the surface of the PDMS elastomer. Because the photoresist is fluorescent, it could be better observed by microscopy, which increased the optical resolution (Figure 8).

Using these substrates and live imaging of cells expressing green fluorescent protein (GFP)-tagged vinculin, it was found that local forces are correlated with the orientation, total fluorescence intensity, and area of the focal adhesions, indicating a constant stress of $5.5 \pm 2 \mathrm{nN} \mu \mathrm{m}^{2}$. The dynamics of the force-dependent modulation of focal adhesions were characterized by blocking actomyosin contractility and were found to be on a time scale of seconds. ${ }^{[93]}$ The aforementioned method enables the study of cell-force mechanics as deformations are easily visualalized and forces calculated.

\subsubsection{Micropillar Substrates}

The embedding of microbeads and micropatterning of elastic substrates enable the study of mechanical interaction of cells on substrates. However, cells can adhere everywhere on such substrates. From a cellular perspective, every cell-substrate contact is linked to the other contacts in the surrounding area, and from the substrate perspective every marker is connected to the markers in and around it. Both of these problems make one option impossible or extremely difficult: the study of the mechanics of a single cell-ECM contact. Topographical substrates consisting of micropillars of variable diameter, height, stiffness, and lateral distances partially address this problem.

Topographic substrates are mostly produced by soft lithography using a mold with defined structure. Consisting of fine needles of different length, which mimic a bed of vertical standing cantilevers, these substrates could be used to measure the cell applied force in a more precise manner as compared to flat elastic substrates. The diameter of the needles could be small enough to support a single contact where the adhered cell and the cell-pillar contacts could be examined independently from each other, which is not possible on a flat substrate because the markers in the substrate stick together making force calculations more complicated.
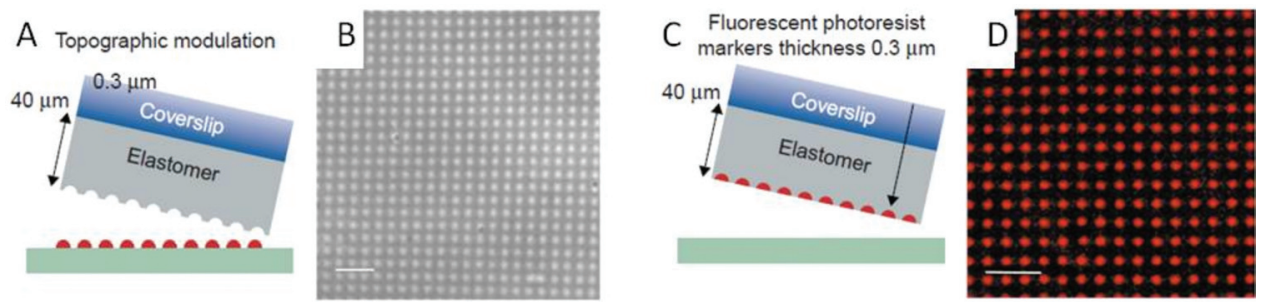

E 1

2

3

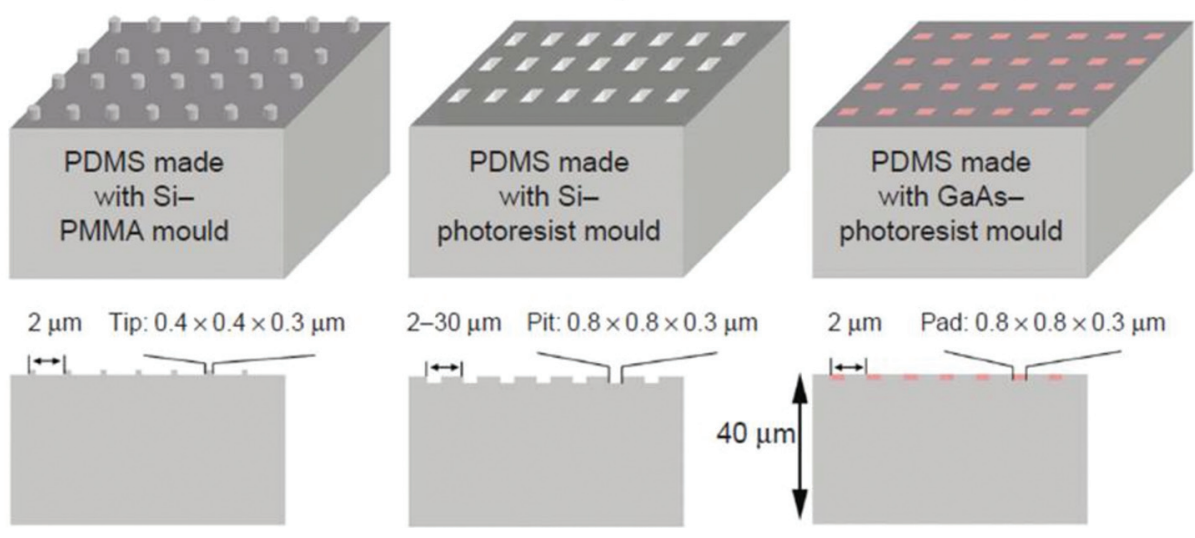

Figure 8. Substrates with regular pattern for traction force microscopy. PDMS substrates with minimal topographical pattern (A,B) or fluorescent pattern (C,D) are prepared by soft lithography. E) Pillars (1) and grooves (2) are prepared using different molds. The fluorescent pattern is created by embedding fluorescent photoresist by separating the elastomer from the mold (3). Reproduced with permission. ${ }^{[93]}$ Copyright 2001 Nature Publishing Group. 
Polymer Micropillars: A widely used material to prepare elastic micropillars is the elastomer PDMS. Tan et al. created such substrates and then modified the height of the pillars by raising the bases of certain pillars, whose tips all lie in one plane. ${ }^{[96]}$ They also created anisotropic stiffness by preparing pillars with an oval cross-section. Another modification realized in this work is the selective functionalization of the pillar tips by microcontact printing, which enables a defined adhesion of cells on the tips. Using these substrates, traction forces of smooth muscle cells and 3 T3 fibroblasts increased with adhesion size, only when the adhesion area was larger than $1 \mu \mathrm{m}^{2}$.

The method developed by Tan et al. has been widely used to quantify cell applied forces by different cell types on various ECM molecules. Elastic micropillars may be bent like vertical cantilevers if cells exert a force on the pillars. This method is used to enhance our understanding of cell mechanics as these flexible pillars are sensitive to cell applied force in the nanonewton range. Sniadecki et al. developed another method to apply external forces to cultivated cells. ${ }^{[2]}$ In this work, a micropillar assay was modified by building magnetic nanowires in the pillars. By application of a magnetic field, the nanowires pass the force to the pillars. If cells make contacts on these pillars, they will be affected by this external force and the deflection of the pillars represent the resultant net force. By varying the length (from 1.4 up to $7 \mu \mathrm{m})$ and the diameter $(1$ and $2 \mu \mathrm{m})$, Ghibaudo et al. could control substrate stiffness over a large range, from 1 to $200 \mathrm{nN} \mathrm{\mu m}^{-1}$. ${ }^{[126]}$ In both 3 T3 fibroblasts and Madin-Darby Canine Kidney (MDCK) epithelial cells, they found that the size of the focal adhesion, spreading area, and cell applied force all increased with the substrate rigidity, whereby the cell applied force was saturated and plateaued for the largest rigidities. Using aligned micropillars, Rossier et al. showed two distinct functions of myosin II in different regions of cellbridging anti-adhesive areas for MEFs and $3 \mathrm{~T} 3$ cells. ${ }^{[133]}$

Mussig et al. tuned the stiffness of pillars by varying the curing time for crosslinking the PDMS elastomer and found that substrate elasticity is important for functional behavior of periodontal cells as indicated by collagen expression. ${ }^{[127]}$ Saez et al. used pillars with an oval cross-section to create substrates with anisotropic rigidity. ${ }^{[78]}$ They found that anisotropy induced directional epithelial growth and guided cell migration in the direction of largest rigidity. Addae-Mensah et al. labeled the tips of the pillars using quantum dots, which does not interfere with ECM molecules, in order to induce cell adhesion and enable the tracking of pillar deflection. ${ }^{[134]}$ By combining micropillars as mechanical sensors and largescale silicone ridges to limit the growth of adult cardiac myocytes, Zhao et al. could control the orientation of the cells in relatively macrosized grooves, and at the same time, they could measure the force using the micropillars underneath the cells. ${ }^{[135]}$ Even PDMS ridges of $15-25 \mu \mathrm{m}$ width and $25 \mu \mathrm{m}$ height could be bent as a result of a force applied by a single osteosacoma cell. ${ }^{[136]}$

Silicon Micropillars: Silicon has numerous advantages as a material for preparing a micropillar assay. The pillar assay may be directly fabricated from silicon metal. The photolithographical process here is similar to manufacturing molds for soft lithography. Petronis et al. prepared micropillars with different heights on the same substrates to vary the stiffness of the pillars such that at the tips of the pillars cells still found a planar surface to grow on (Figure 9). ${ }^{[137]}$ Due to a very thin diameter, the pillars are flexible and could be used to sense cell mechanics. To increase the flexibility and thus sensitivity of the pillars, they could be etched in conical form, so they become even thinner at the base. The length/height of the pillars can be varied, and they could also be embedded in a surface of the same height, so that cells could grow on the surface and the force applied by contacts on single pillars could be calculated. The silicon pillar is sensitive enough to measure cell applied forces, but it has a few drawbacks in practice. First, silicon substrates can only be used once, and the preparation is relatively expensive. In addition, the pillars are very sensitive but also very fragile. They may be bent and easily broken by cell applied forces. These characteristics limit the broad application of this method.

\subsubsection{D Elastic Structures}

The three-dimensionality as well as biochemical composition and mechanical properties play a significant role in controlling cell behaviors such as migration, proliferation, biosynthesis, and response to apoptotic signals. ${ }^{[138]}$ Knowledge about the effect of dimensionality is mostly gained from cell cultures in different compact gels-mostly collagen or cell-derived matrices ${ }^{[139]}$ _because they mimic the extracellular environment without any further functionalization. These materials are biodegradable due to their natural origin and can be metabolized and reorganized from cultivated cells. Scaffolds provided by these natural materials are random aggregations and orientations of protein fibers, which makes evaluation difficult. To create more defined substrates, which is important in research and clinical applications, ${ }^{[140]} 3 \mathrm{D}$ scaffolds consisting of synthetic polymers, ceramics, or metal are introduced. These materials afford enhanced manufacturing control and mechanical stability. Currently scaffolds with micrometer and sub-micrometer range, which provide an opportunity to monitor the behavior of a single cell in a totally defined 3D environment, can be produced. ${ }^{[99,141]}$ Here we will summarize these studies and detail fabrication strategies of 3D substrates and the impacts of these substrates on cell biology.

Photolithographic Resins of 3D Structures: Photopolymerization of different elastomers enable precise preparation of cell culture substrates with three-dimensionally defined scaffolds. ${ }^{[99]}$ Direct laser writing (DLW) methods and surface functionalization were used to prepare beam structures which could be deflected by a single beating chick embryonic cardiomyocyte (Figure 10). Atomic force microscopy (AFM) calibration showed the stiffness of the Ormocer structure depends on its diameter and as beam diameter increased, beam deflection decreased. For example, a beam diameter of $660 \mathrm{~nm}$ was deflected $800 \mathrm{~nm}$ by an applied force of $47 \mathrm{nN}$. This method provides a novel means of creating highly controlled 3D scaffolds, which may be utilized in cell growth studies. The use of a 3D environment more closely mimics in vivo conditions and is therefore advantageous to the $2 \mathrm{D}$ planar environments commonly utilized. 
A Patterning of photoresist

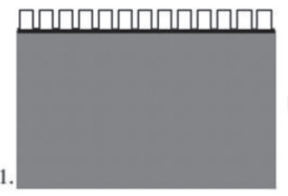

Etching of $\mathrm{Si}$

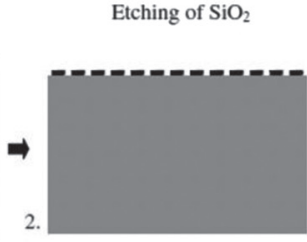

Removing of photoresist

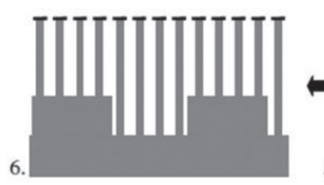

Etching of $\mathrm{SiO}_{2}$

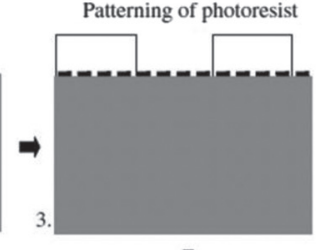

1

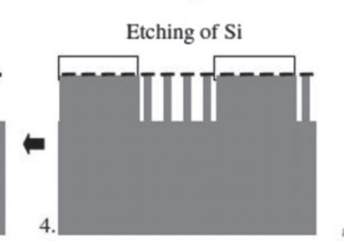

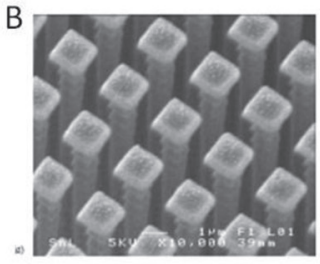

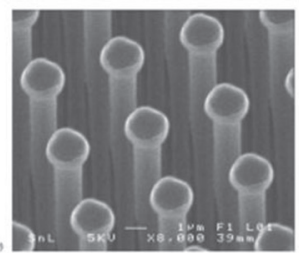

Figure 9. Pillar substrates made from silicon metal. A) Schematic for preparing pillar substrates with different height by double etching. B) SEM pictures for pillar substrates. Reproduced with permission. ${ }^{[137]}$ Copyright 2003 Insitute of Physics.

Recently, Klein et al. extended this work using DLW to fabricate composite scaffolds with distinct protein binding properties. ${ }^{[142]}$ The two-component scaffold comprised polyethylene glycol diacrylate (PEG-DA) and pentaerythritol tetra-acrylate (PETA). Ormocomp square patterns were embedded in PEG-DA background with increasing concentrations of PETA. Patterns and backgrounds with PETA concentrations of $0-100 \%$ PETA (w/w) were incubated with the protein fibronectin and then seeded with chicken fibroblast cells. Below 4.8\% PETA (w/w), the scaffold was protein repellant and cells only adhered to the Ormocomp patterns. However, above $4.8 \%$ PETA (w/w) cells spread on both the square patterns and the PEFG-DA/PETA background. This method provides control over the formation of cell adhesion sites, and consequently, the cell shape in three dimensions. As a result, cell growth can be directed in three dimensions.

Using a two-photon laser scanning photolithographic technique, the cell adhesive ligand arginine-glycine-asparticacid-serine (RGDS) was immobilized in a hydrogel that was (a)

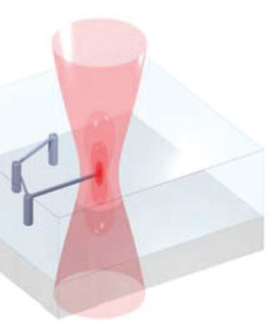

(b)

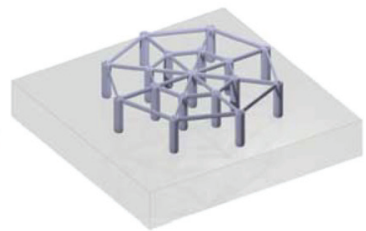

(c)

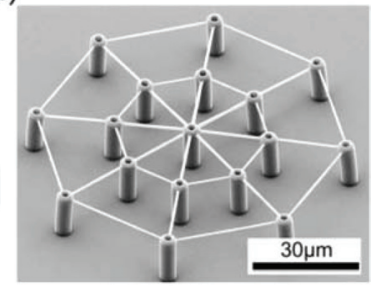

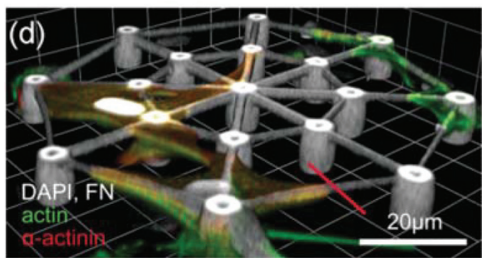

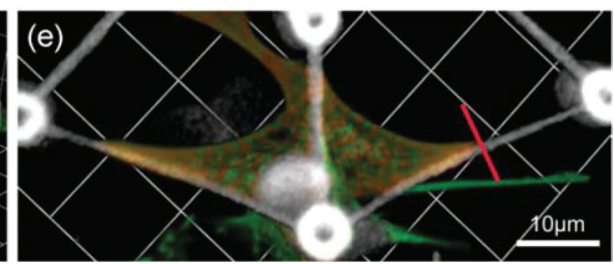

Figure 10. Micropillars created via DLW. a,b) Scheme illustrating DLW, in which a photoresist is exposed to a laser focus (red region) via two-photon absorption. Scanning of the laser focus with respect to the resist results in 3D structures. c) SEM of a 3D scaffold. d,e) 3D reconstruction of a confocal image stack of chicken cardiomyocytes grown in an Ormocomp scaffold consisting of posts connected by beams with a diameter of $0.6 \mu \mathrm{m}$ (oblique view (d); top view (e)). Labeling for f-actin and a-actinin illustrates the formation of regular myofibrils. Reproduced. ${ }^{[99]}$ collagenase-sensitive. ${ }^{[101]}$ The micropatterned hydrogel was generated via a series of photolithographic, soaking, and laser scanning steps (Figure 11). Human dermal fibroblasts (HDFs) seeded within the micropatterned hydrogel exhibited directed cell migration and growth along the RGD immobilized regions. This work has applications in tissue engineering as a platform for providing biological cues in a $3 \mathrm{D}$ environment to stimulate tissue regeneration.

Pressure-assisted microsyringe (PAM) is another photolithographic technique that has been used to generate $3 \mathrm{D}$ constructs from hydrogels and biodegradable polymers. ${ }^{[143]}$ This technique affords high lateral resolution, in the $5 \mu \mathrm{m}$ range, which results in intricate architectures. In particular, it has been utilized to investigate the influence of defined $3 \mathrm{D}$ topographies and stiffness on cell behavior. ${ }^{[144]}$ This work found that irrespective of cell type, scaffolds fabricated via the PAM technique had enhanced cell adhesion and lineagespecific cytoskeletal organization as compared to controls of random architecture. ECM-mimicking 3D architectures have also been found to influence the behavior of tumor cells. For example, matrix stiffness as well as adhesion and tractile forces impact the migration of cancer cells. ${ }^{[145]}$

Microfabrication and Soft Lithography: Recently, 3D scaffolds comprising PDMS with precise micro-architecture and microtextures have been created by soft lithography to investigate the in vitro differentiation of mesenchymal stem cells. ${ }^{[100]}$ 3D scaffolds were generated starting with the microfabrication of a mold using an SU8 photoresist and then the molding of PDMS with a mechanical jig which is followed by the alignment, stacking, and adhesion of subsequent PDMS layers. Textured scaffolds consisted of $10 \mu \mathrm{m}$ diameter/height posts, and cell behavior on these surfaces was compared to that which is observed on smooth 3D scaffolds (Figure 12). Cells were cultured under conditions favorable for osteogenic differentiation, and results indicated that cells 

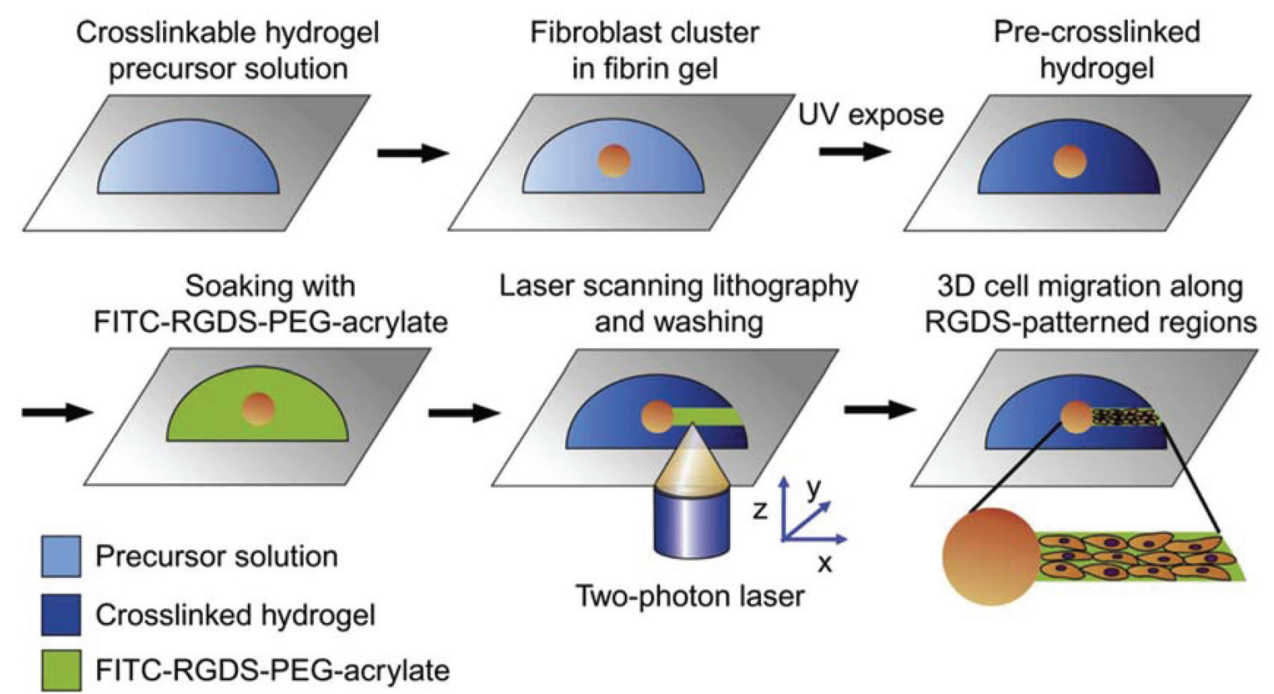

Figure 11. The overall methodology for 3D arginine-glycine-aspartic-acid-serine (RGDS) patterning by two-photon laser scanning (TPLS) photolithography. First, HDFs encapsulated in fibrin clusters were photopolymerized into collagenase-sensitive PEG hydrogels by exposure to longwavelength UV light. The hydrogels were soaked in PEG-RGDS solution, allowing its diffusion into the bulk materials. The TPLS photolithographic technique was used to irradiate the hydrogels according to the predesigned virtual patterns, conjugating PEG-RGDS into a 3D network of hydrogels in predetermined patterns. After washing steps, cell migration was subsequently monitored over time. FITC represents fluorescein isothiocyanate. Reproduced with permission. ${ }^{[101]}$ Copyright 2008 Elsevier.

cultured on textured 3D scaffolds had increased cell numbers and expression of alkaline phosphotase, an osteogenic marker, as compared to those cultured on smooth surfaces.

A combination of microfabrication and soft lithography was utilized to create a micropatterned, biopolymer 3D scaffold via lamination of micropatterned membranes fabricated by soft lithography. ${ }^{[146]}$ In this instance, scaffolds with hexagonal geometry were cultured with fibroblasts in both static and dynamic environments. Sufficient fibroblast adhesion was apparent in both static and dynamic conditions, though excessive flow rate resulted in decreased cell adhesion. In addition, tissue geometry has been found to determine the site of mammary branching morphogenesis, which has implications in tumor invasion and metastisis. ${ }^{[147]}$

Tougher 3D Structures: Although the focus of this review is on elastic substrates, harder 3D substrates are also utilized in cell studies and are thus briefly introduced in the descriptions that follow. Micro-stereolithography has been used to fabricate a scaffold of a photopolymer, poly(propylene fumarate) (PPF). Here scaffolds were created by dividing the photopolymer into several horizontal slices and hardening said slices with a laser beam before stacking them to generate the desired shape (Figure 13). These hard scaffolds mimic the mechanical properties of bone and were suitable for the cultivation of fibroblasts. ${ }^{[148]}$ Regulation of axon guidance and extension may also be controlled via 3D structures and constraints. ${ }^{[149]}$

Scaffolds for 3D cell culture have also been generated from porous alginate/polyvinyl alcohol. ${ }^{[150]}$ The composition of hybrid scaffolds was varied by altering the weight percentage of PVA incorporated, and scaffolds were engineered via freeze-drying processes and crosslinking steps. Chondrocytes were cultured on the scaffolds for a range of time points from one day to four weeks. As compared to alginateonly scaffolds, hybrid scaffolds had enhanced cell adhesion and faster growth. Among metallic scaffolds, porous titanium scaffolds with controlled structure and high strength have been created using a combination of rapid prototyping and powder metallurgy techniques. ${ }^{[18]}$ In addition to scaffolds, gel-free microfluidic cell culture systems may be used to simulate 3D cell culture via the use of transient intercellular polymeric linkers and microfabricated pillar arrays. ${ }^{[19]}$

\subsubsection{Elastic Gradients}

Due to the fact that cells sense and respond to substrate elasticity, it is interesting to know how cells react to the difference in elasticity over a single substrate. Most elastic substrates have one constant stiffness, and cell reactions were investigated on different substrates with relevant stiffness. In vivo, cells may experience a range of elastic properties, and as such a substrate with continuous elasticity gradient would be extremely useful. Different parts of the cell are located on various points of the gradient substrates in order to get different mechanical inputs, and as such the cell response should reflect this difference. In the last few years, methods for preparing such substrates to investigate cell behavior were introduced. Substrates typically consist of different gels with natural or synthetic origin. The general principle of these methods is controlling the gradient of polymerization. While some of these methods use physical processes such as pressing a wedge-shaped gel ${ }^{[103]}$ or interdiffusion of two components, ${ }^{[122]}$ most are generated by defined photo-irradiation to control the polymerization of the prepolymer or the degradation of the photosensitive polymer. 
SU-8 Mold
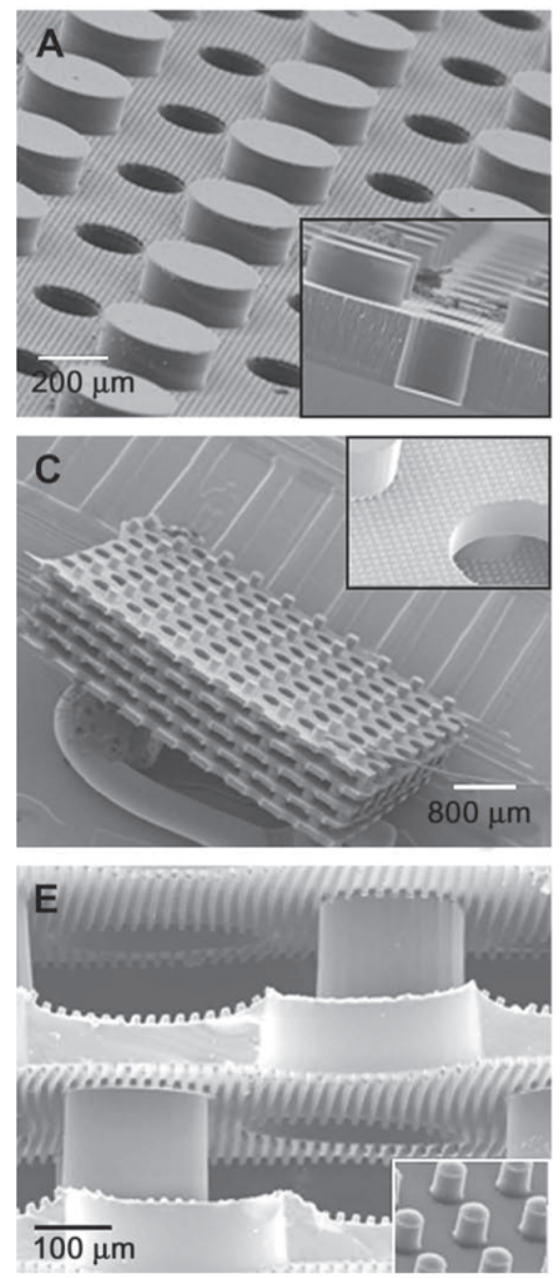

PDMS Layer
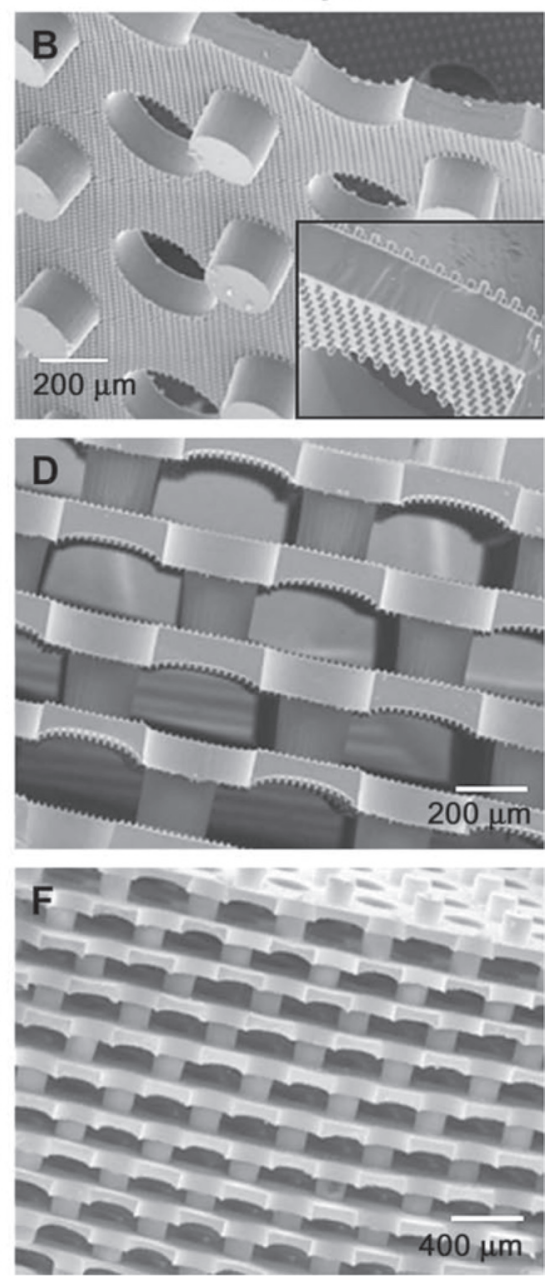

Figure 12. SEM images. A) Resulting SU-8 mold with a cross-section (inset), and B) dualsided molded PDMS layer with $300 \mu \mathrm{m}$ diameter and $100 \mu \mathrm{m}$ depth through holes, $200 \mu \mathrm{m}$ diameter and $200 \mu \mathrm{m}$ high columns, and $10 \mu \mathrm{m}$ diameter and $10 \mu \mathrm{m}$ high posts on both sides of the layer (inset). SEM images exemplify C) five-layer PDMS scaffold on a penny, D) magnification of the cross-section showing the alignment between adjacent layers that resulted in a meandering pore geometry, and E) $10 \mu \mathrm{m}$ diameter and $10 \mu \mathrm{m}$ high posts present on all horizontal surfaces. F) Scaffold height was increased by adding more PDMS layers. Reproduced with permission. ${ }^{[100]}$ Copyright 2009 Elsevier.

The first substrate with elastic gradients were PAA gels consisting of two parts with different concentrations of BIS, and at the boundary was an area of a few tens of micrometers with continuous varying stiffness. ${ }^{[118]}$ In this work, two PAA mixtures were placed side by side on one cover slip and another cover slip was placed on top of the solutions. Both solutions began to mix with each other before the solutions
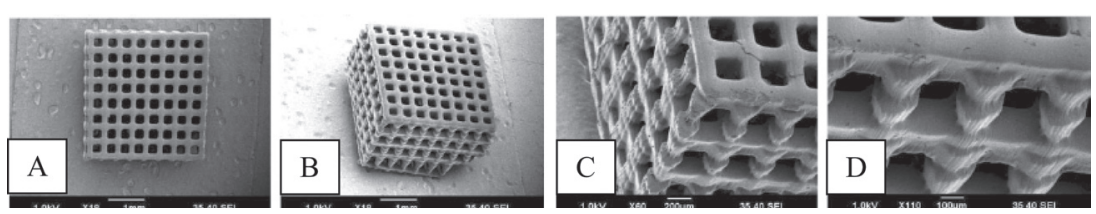

Figure 13. SEM images of the 3D scaffold with $0.5 \mathrm{~mm}$ line pitch. A) Top view (scale bar = $1 \mathrm{~mm}$ ), B) diagonal view (scale bar $=1 \mathrm{~mm}$ ), C) magnification (scale bar $=200 \mu \mathrm{m}$ ), and D) magnification (scale bar $=100 \mu \mathrm{m}$ ). Reproduced with permission. ${ }^{[148]}$

became gels and built a continuous gradient of stiffness. The authors found that $3 \mathrm{~T} 3$ cells prefer to migrate from the soft to the hard part of the substrate and defined this behavior as durotaxis. CroweWilloughby et al. used the same principle but two other elastomers, PDMS and poly(vinylmethylsiloxane) (PVMS), were used to fabricate the elastic gradient. [122] Because polymerization occurs after interdiffusion, the two components had sufficient time to mix with each other and could produce gradients from 20 to $400 \mathrm{kPa}$ distributed over a distance of up to $30 \mathrm{~cm}$. Microfluidic network methods used to generate substrate-bound ECM gradients is a general technique based on interdiffusion and has also been used in combination to prepare substrates with elastic gradients. ${ }^{[22,151]}$ Isenberg et al. varied the working elasticity of a PAA gel from 1 to $80 \mathrm{kPa}$ at a distance of $1500 \mu \mathrm{m}$. Some limitations of the interdiffusion process restrict the application of the method. First of all, it is not possible to control the extent of the gradient in a precise manner due to undefined diffusion. Additionally, because each formulation to interdiffuse comprises a two or more component mixture, the distribution of these components in the final network may not be uniform and that would ultimately lead to a certain uncontrolled "skew" of the gradient. Finally, the surface characteristics of the individual formulations may vary to some extent, which will ultimately affect the application of such gradient structures in biological studies. ${ }^{[122]}$

In comparison, photopolymerization is better controlled and can be used to manufacture better-defined elastic gradients. The variables here are the distribution of the photo-initiators and irradiation intensity and time. The possible ways for generating a gradient are: 1) irradiation of a pre-elastomer with gradually distributed photo-initiator, which could be prepared via microfluidic networks, with constant time and intensity; 2) irradiation through a mask with gradual transparency for a constant time on a prepolymer with uniformly distributed initiator; 3) varying the time of irradiation through the length of the substrate by constant intensity and uniform distribution of initiator (Figure 14). The variation of two or more variables offers additional possibilities to tune the gradient. The use of an initiator for photo-induced degradation instead of polymerization can change the direction of the aimed gradient. Crowe-Willoughby et al. used the photo masks with linear 
Conditions

(1)

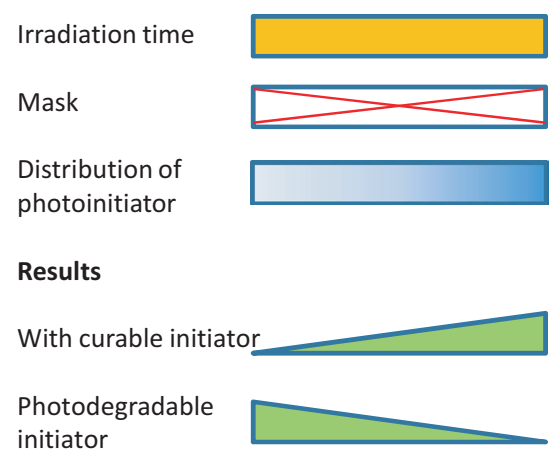

(2)
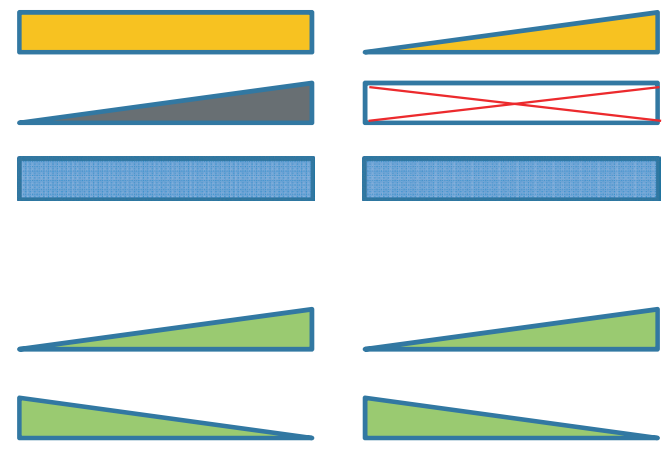

Figure 14. Principle of creating elastic gradient by photo-crosslinking/degradation. Variation of three variables leads to gradual gradients depending on the type of photo-initiators. 1) Gradually distributed photo-initiator. 2) Gradual intensity goes through the mask. 3) Irradiation time increases gradually from one side to the other side of the substrate.

or radial gradual transmittance to manufacture mercaptoterminated poly(vinylmethylsiloxane) PVMS-SH elastomer with elastic gradient. ${ }^{[122]}$ Wong et al. also fabricated a radial elastic gradient from 2 to $11 \mathrm{kPa}$ on PAA gels using a mask while Kidoaki et al. used a simple unilateral mask to prepare photocurable styrenated gelatin gel with an elastic gradient from 10 to $400 \mathrm{kPa}$. ${ }^{[102]}$

Kloxin et al. varied the time of irradiation to tune the elasticity of the substrates. ${ }^{[123]}$ In this instance, a photodegradable initiator PEG diacrylate crosslinking macromer (PEGdiPDA) was used. The initiator was first polymerized in PEG monoacrylate (PEGA) gel, and the gel was irradiated by $365 \mathrm{~nm}$ wavelength. The continuous motion of an opaque plate with constant velocity over the gels created an elasticity gradient from 10 to $30 \mathrm{kPa}$ through the length of $9 \mathrm{~mm}$. Kidoaki et al. also modified the absolute stiffness and steepness of the gradient by varying the irradiation time when they prepared elastic gradients using a mask. ${ }^{[102]}$

Hadjipanayi et al. used mechanical instead of chemical processing to produce cell culture substrates with elastic gradients. ${ }^{[103]}$ They first prepared a wedge-shaped collagen gel and then compressed it to a thin film of $0.1 \mathrm{~mm}$. The density of collagen matrix increased continuously from the cone to the high end as did the stiffness. Elasticity increases continuously from 1000 to $2300 \mathrm{kPa}$ over the length of the substrates.

\section{Summary \& Outlook}

A wide range of materials and fabrication methods for designing substrates to investigate the influence of the physical environment on cell behavior has been detailed in this review. Extensive work has been undertaken to determine the impact of the physical environment on a wide array of cell types with responses being cell-type dependent. Currently, research is hampered by the fact that a myriad of factors simultaneously contribute to cell behavior. It is therefore difficult to elucidate single modes of mechanisms. In the past, fabrication and analysis techniques hindered the ability to study single cells. However, recent advances in micro- and nanofabrication have made such studies more desirable.
Advances in these areas have also afforded the opportunity to examine cell behavior in $3 \mathrm{D}$ rather than $2 \mathrm{D}$ environments enabling researchers to better mimic and analyze cell response in vivo. These $3 \mathrm{D}$ studies are expected to provide novel insights into the cellular response to surface topography, roughness, and elasticity. While poly(dimethylsiloxane) has been a model elastic substrate previously, the materials community is increasingly developing an array of defined substrates, including photo-crosslinkable hydrogels, which could be of use in ascertaining in vitro cell-surface interactions going forward. With enhanced processes and materials, investigating the physical environment's role on cell behavior is a rich and promising research area, which could impact a wealth of biomedical applications.

\section{Acknowledgements}

A.M.R acknowledges support from a graduate fellowship from the National Institutes of Health through the University of Michigan Microfluidics and Biomedical Sciences Training grant (T32 EB005582-06). Work in the lab of M.B. is supported by the Deutsche Forschungsgemeinschaft (DFG) and the State of Baden-Württemberg through the DFG-Center for Functional Nanostructures (CFN) within subproject E2.3.

[1] B. Geiger, J. P. Spatz, A. D. Bershadsky, Nat. Rev. Mol. Cell Biol. 2009, 10, 21.

[2] N. J. Sniadecki, A. Anguelouch, M. T. Yang, C. M. Lamb, Z. Liu, S. B. Kirschner, Y. Liu, D. H. Reich, C. S. Chen, Proc. Nat. Acad. Sci. USA 2007, 104, 14553.

[3] M. J. Dalby, M. O. Riehle, D. S. Sutherland, H. Agheli, A. S. G. Curtis, Eur. J. Cell Biol. 2004, 83, 159.

[4] J. H. Huang, S. V. Grater, F. Corbellinl, S. Rinck, E. Bock, R. Kemkemer, H. Kessler, J. D. Ding, J. P. Spatz, Nano Lett. 2009, 9, 1111.

[5] M. J. Dalby, N. Gadegaard, R. Tare, A. Andar, M. O. Riehle, P. Herzyk, C. D. W. Wilkinson, R. O. C. Oreffo, Nat. Mater. 2007, 6, 997.

[6] M. Arnold, M. Schwieder, J. Blummel, E. A. Cavalcanti-Adam, M. Lopez-Garcia, H. Kessler, B. Geiger, J. P. Spatz, Soft Matter 2009, 5, 72 . 
[7] M. M. Stevens, J. H. George, Science 2005, 310, 1135.

[8] D. Lehnert, B. Wehrle-Haller, C. David, U. Weiland, C. Ballestrem, B. A. Imhof, M. Bastmeyer, J. Cell Sci. 2004, 117, 41.

[9] N. M. Alves, I. Pashkuleva, R. L. Reis, J. F. Mano, Small 2010, 6, 2208.

[10] P. Molnar, W. S. Wang, A. Natarajan, J. W. Rumsey, J. J. Hickman, Biotechnol. Prog. 2007, 23, 265.

[11] H. Hatakeyama, A. Kikuchi, M. Yamato, T. Okano, Biomaterials 2007, 28, 3632.

[12] G. M. Whitesides, E. Ostuni, S. Takayama, X. Y. Jiang, D. E. Ingber, Annu. Rev. Biomed. Eng. 2001, 3, 335.

[13] S. Y. Chou, C. M. Cheng, P. R. Leduc, Biomaterials 2009, 30 , 3136.

[14] A. J. Engler, S. Sen, H. L. Sweeney, D. E. Discher, Cell 2006, 126, 677.

[15] C. Galli, G. Passeri, F. Ravanetti, E. Elezi, M. Pedrazzoni, G. M. Macaluso, J. Biomed. Mater. Res., Part A 2010, 95A, 682.

[16] J. Gong, O. Sagiv, H. Cai, S. H. Tsang, L. V. Del Priore, Exp. Eye Res. 2008, 86, 957.

[17] F. H. Chen, R. S. Tuan, Arthritis Res. Ther. 2008, 10, 12.

[18] G. E. Ryan, A. S. Pandit, D. P. Apatsidis, Biomaterials 2008, 29 , 3625.

[19] S. M. Ong, C. Zhang, Y. C. Toh, S. H. Kim, H. L. Foo, C. H. Tan, D. van Noort, S. Park, H. Yu, Biomaterials 2008, 29, 3237.

[20] R. M. Tenney, D. E. Discher, Curr. Opin. Cell Biol. 2009, 21, 630.

[21] F. Guilak, D. M. Cohen, B. T. Estes, J. M. Gimble, W. Liedtke, C. S. Chen, Cell Stem Cell 2009, 5, 17.

[22] N. Zaari, P. Rajagopalan, S. K. Kim, A. J. Engler, J. Y. Wong, Adv. Mater. 2004, 16, 2133.

[23] A. Curtis, C. Wilkinson, Biomaterials 1997, 18, 1573.

[24] H. Jeon, H. Hidai, D. J. Hwang, C. P. Grigoropoulos, J. Biomed. Mater. Res. Part A 2010, 93A, 56.

[25] H. Hidai, H. Jeon, D. J. Hwang, C. P. Grigoropoulos, Biomed. Microdevices 2009, 11, 643.

[26] J. Y. Mai, C. Sun, S. Li, X. Zhang, Biomed. Microdevices 2007, 9 , 523.

[27] E. K. F. Yim, R. M. Reano, S. W. Pang, A. F. Yee, C. S. Chen, K. W. Leong, Biomaterials 2005, 26, 5405.

[28] D. H. Kim, C. H. Seo, K. Han, K. W. Kwon, A. Levchenko, K. Y. Suh, Adv. Funct. Mater. 2009, 19, 1579.

[29] P. Clark, P. Connolly, A. S. G. Curtis, J. A. T. Dow, C. D. W. Wilkinson, Development 1987, 99, 439.

[30] P. Clark, P. Connolly, A. S. G. Curtis, J. A. T. Dow, C. D. W. Wilkinson, Development 1990, 108, 635.

[31] D. H. Kim, K. Han, K. Gupta, K. W. Kwon, K. Y. Suh, A. Levchenko, Biomaterials 2009, 30, 5433.

[32] J. P. Kaiser, A. Reinmann, A. Bruinink, Biomaterials 2006, 27, 5230.

[33] M. D. Krebs, K. A. Sutter, A. S. P. Lin, R. E. Guldberg, E. Alsberg, Acta Biomater. 2009, 5, 2847.

[34] M. Shi, M. S. Shoichet, J. Biomater. Sci.-Polym. Ed. 2008, 19, 1143.

[35] C. J. Pan, J. J. Tang, Y. J. Weng, J. Wang, N. Huang, J. Control. Release 2006, 116, 42

[36] M. S. Lord, M. Foss, F. Besenbacher, Nano Today 2010, 5, 66.

[37] J. R. Sun, Y. F. Ding, N. J. Lin, J. Zhou, H. Ro, C. L. Soles, M. T. Cicerone, S. Lin-Gibson, Biomacromolecules 2010, 11, 3067.

[38] L. Altomare, N. Gadegaard, L. Visai, M. C. Tanzi, S. Fare, Acta Biomater. 2010, 6, 1948

[39] E. Lamers, X. F. Walboomers, M. Domanski, J. te Riet, F. van Delft, R. Luttge, L. Winnubst, H. Gardeniers, J. A. Jansen, Biomaterials 2010, 31, 3307.

[40] F. S. M. Ismail, R. Rohanizadeh, S. Atwa, R. S. Mason, A. J. Ruys, P. J. Martin, A. Bendavid, J. Mater. Sci.-Mater. Med. 2007, 18, 705.

[41] M. Ghibaudo, L. Trichet, J. Le Digabel, A. Richert, P. Hersen, B. Ladoux, Biophys. J. 2009, 97, 357.
[42] W. A. Loesberg, J. te Riet, F. van Delft, P. Schon, C. G. Figdor, S. Speller, J. van Loon, X. F. Walboomers, J. A. Jansen, Biomaterials 2007, 28, 3944.

[43] I. Milosev, Pure Appl. Chem. 2010, 83, 309.

[44] G. Laszlo, P. Anita, E. Vazsonyi, M. Gergely, D. Guban, R. Fiath, B. P. Kerekes, K. Gyorgy, U. Istvan, B. Gabor, Sens. Actuator A-Phys. 2011, 166, 14.

[45] G. Zhao, Z. Schwartz, M. Wieland, F. Rupp, J. Geis-Gerstorfer, D. L. Cochran, B. D. Boyan, J. Biomed. Mater. Res. Part A 2005, $74 A, 49$.

[46] G. Zhao, O. Zinger, Z. Schwartz, M. Wieland, D. Landolt, B. D. Boyan, Clin. Oral Implant. Res. 2006, 17, 258.

[47] A. M. P. Turner, N. Dowell, S. W. P. Turner, L. Kam, M. Isaacson, J. N. Turner, H. G. Craighead, W. Shain, J. Biomed. Mater. Res. 2000, 51, 430.

[48] J. Lu, M. P. Rao, N. C. MacDonald, D. Khang, T. J. Webster, Acta Biomater. 2008, 4, 192.

[49] C. J. Bettinger, R. Langer, J. T. Borenstein, Angew. Chem., Int. Ed. 2009, 48, 5406

[50] F. Luthen, R. Lange, P. Becker, J. Rychly, U. Beck, J. G. B. Nebe, Biomaterials 2005, 26, 2423.

[51] C. Larsson, P. Thomsen, B. O. Aronsson, M. Rodahl, J. Lausmaa, B. Kasemo, L. E. Ericson, Biomaterials 1996, 17, 605.

[52] N. A. Kotov, J. O. Winter, I. P. Clements, E. Jan, B. P. Timko, S. Campidelli, S. Pathak, A. Mazzatenta, C. M. Lieber, M. Prato, R. V. Bellamkonda, G. A. Silva, N. W. S. Kam, F. Patolsky, L. Ballerini, Adv. Mater. 2009, 21, 3970.

[53] B. Feng, J. Weng, B. C. Yang, S. X. Qu, X. D. Zhang, Biomaterials 2003, 24, 4663.

[54] L. Montanaro, C. R. Arciola, D. Campoccia, M. Cervellati, Biomaterials 2002, 23, 3651.

[55] Z. H. Nie, E. Kumacheva, Nat. Mater. 2008, 7, 277.

[56] I. Y. Tsai, A. J. Crosby, T. P. Russell, Cell Mechanics 2007, 83, 67.

[57] R. D. Piner, J. Zhu, F. Xu, S. Hong, C. A. Mirkin, Science 1999, 283,661

[58] S. Y. Chou, P. R. Krauss, P. J. Renstrom, Science 1996, 272, 85.

[59] V. N. Truskett, M. P. C. Watts, Trends Biotechnol. 2006, 24 , 312.

[60] S. M. Yang, S. G. Jang, D. G. Choi, S. Kim, H. K. Yu, Small 2006, 2, 458.

[61] B. D. Boyan, T. W. Hummert, D. D. Dean, Z. Schwartz, Biomaterials 1996, 17, 137

[62] B. D. Boyan, C. H. Lohmann, D. D. Dean, V. L. Sylvia, D. L. Cochran, Z. Schwartz, Annu. Rev. Mater. Res. 2001, 31, 357.

[63] K. T. Bowers, J. C. Keller, B. A. Randolph, D. G. Wick, C. M. Michaels, Int. J. Oral Maxillofac. Implants 1992, 7, 302.

[64] D. L. Cochran, J. Simpson, P. Weber, D. Buser, M. Med Dent, Int. J. Oral Maxillofac. Implants 1994, 9, 289.

[65] C. Y. Jin, B. S. Zhu, X. F. Wang, Q. H. Lu, W. T. Chen, X. J. Zhou, J. Mater. Sci.-Mater. Med. 2008, 19, 2215.

[66] M. Wang, Y. Lu, Surf. Coat. Technol. 2009, 204, 525.

[67] H. Shadpour, N. L. Allbritton, ACS Appl. Mater Interfaces. 2010 , 2, 1086.

[68] A. Thapa, D. C. Miller, T. J. Webster, K. M. Haberstroh, Biomaterials 2003, 24, 2915.

[69] R. J. Zdrahala, I. J. Zdrahala, J. Biomater. Appl. 1999, 14, 67.

[70] A. Thapa, T. J. Webster, K. M. Haberstroh, J. Biomed. Mater. Res. Part A 2003, 67A, 1374.

[71] L. Zhang, T. J. Webster, Nano Today 2009, 4, 66.

[72] Y. W. Chun, D. Khang, K. M. Haberstroh, T. J. Webster, Nanotechnology 2009, 20.

[73] D. C. Meng, M. Erol, A. R. Boccaccini, Adv. Eng. Mater. 2010, 12, B467.

[74] S. Affrossman, M. Stamm, Colloid Polym. Sci. 2000, 278, 888.

[75] J. Y. Lim, J. C. Hansen, C. A. Siedlecki, J. Runt, H. J. Donahue, J. R. Soc. Interface. 2005, 2, 97. 
[76] D. Docheva, D. Padula, C. Popov, W. Mutschler, H. Clausen-Schaumann, M. Schieker, J. Cell. Mol. Med. 2008, $12,537$.

[77] R. J. Pelham, Y. L. Wang, Proc. Natl. Acad. Sci. USA 1997, 94, 13661.

[78] A. Saez, M. Ghibaudo, A. Buguin, P. Silberzan, B. Ladoux, Proc. Natl. Acad. Sci. USA 2007, 104, 8281.

[79] A. L. Plant, K. Bhadriraju, T. A. Spurlin, J. T. Elliott, BBA-Mol. Cell Res. 2009, 1793, 893.

[80] Masurovs. Eb, E. R. Peterson, Exp. Cell Res. 1973, 76, 447.

[81] E. Kniazeva, A. J. Putnam, AM. J. Physio-Cell. Ph. 2009, 297, C179.

[82] A. P. Balgude, X. Yu, A. Szymanski, R. V. Bellamkonda, Biomaterials 2001, 22, 1077.

[83] N. G. Genes, J. A. Rowley, D. J. Mooney, L. J. Bonassar, Arch. Biochem. Biophys. 2004, 422, 161.

[84] R. W. Tilghman, C. R. Cowan, J. D. Mih, Y. Koryakina, D. Gioeli, J. K. Slack-Davis, B. R. Blackman, D. J. Tschumperlin, J. T. Parsons, Plos One 2010, 5.

[85] L. Kocgozlu, P. Lavalle, G. Koenig, B. Senger, Y. Haikel, P. Schaaf, J. C. Voegel, H. Tenenbaum, D. Vautier, J. Cell Sci. 2010, 123, 29.

[86] E. M. Horn, M. Beaumont, X. Z. Shu, A. Harvey, G. D. Prestwich, K. M. Horn, A. R. Gibson, M. C. Preul, A. Panitch, J. Neurosurg. 2007, 6, 133.

[87] C. S. Hughes, L. M. Postovit, G. A. Lajoie, Proteomics 2010, 10, 1886.

[88] K. R. Levental, H. M. Yu, L. Kass, J. N. Lakins, M. Egeblad, J. T. Erler, S. F. T. Fong, K. Csiszar, A. Giaccia, W. Weninger, M. Yamauchi, D. L. Gasser, V. M. Weaver, Cell 2009, 139, 891.

[89] K. Ghosh, D. E. Ingber, Adv. Drug Delivery Rev. 2007, 59, 1306.

[90] Y. S. Pek, A. C. A. Wan, J. Y. Ying, Biomaterials 2010, 31, 385.

[91] J. le Digabel, M. Ghibaudo, L. Trichet, A. Richert, B. Ladoux, Med. Biol. Eng. Comput 2010, 48, 965.

[92] A. K. Harris, P. Wild, D. Stopak, Science 1980, 208, 177.

[93] N. Q. Balaban, U. S. Schwarz, D. Riveline, P. Goichberg, G. Tzur, I. Sabanay, D. Mahalu, S. Safran, A. Bershadsky, L. Addadi, B. Geiger, Nat. Cell Biol. 2001, 3, 466.

[94] R. Merkel, N. Kirchgebner, C. M. Cesa, B. Hoffmann, Biophys. J. 2007, 93, 3314.

[95] J. P. Rieu, C. Barentin, Y. Maeda, Y. Sawada, Biophys. J. 2005, $89,3563$.

[96] J. L. Tan, J. Tien, D. M. Pirone, D. S. Gray, K. Bhadriraju, C. S. Chen, Proc. Natl. Acad. Sci. USA 2003, 100, 1484.

[97] O. du Roure, A. Saez, A. Buguin, R. H. Austin, P. Chavrier, P. Silberzan, B. Ladoux, Proc. Natl. Acad. Sci. USA 2005, 102, 2390.

[98] S. W. Moore, N. Biais, M. P. Sheetz, Science 2009, 325, 166.

[99] F. Klein, T. Striebel, J. Fischer, Z. X. Jiang, C. M. Franz, G. von Freymann, M. Wegener, M. Bastmeyer, Adv. Mater. 2010, 22, 868.

[100] A. Mata, E. J. Kim, C. A. Boehm, A. J. Fleischman, G. F. Muschler, S. Roy, Biomaterials 2009, 30, 4610.

[101] S. H. Lee, J. J. Moon, J. L. West, Biomaterials 2008, 29, 2962.

[102] A. Kidoaki, T. Matsuda, J. Biotechnol. 2008, 133, 225.

[103] E. Hadjipanayi, V. Mudera, R. A. Brown, Cell Motil. Cytoskeleton 2009, 66, 121

[104] L. E. Nielsen, R. F. Landel, Mechanical Properties of Polymer and Composites, 2nd ed., Marcel Dekker, Inc., New York, 1994.

[105] F. X. Jiang, B. Yurke, B. L. Firestein, N. A. Langrana, Ann. Biomed. Eng. 2008, 36, 1565.

[106] J. Kim, Y. Park, G. Tae, K. B. Lee, S. J. Hwang, I. S. Kim, I. Noh, K. Sun, J. Mater. Sci.: Mater. Med. 2008, 19, 3311.

[107] S. B. Anderson, C.-C. Lin, D. V. Kuntzler, K. S. Anseth, Biomaterials 2011, 32, 3564.

[108] R. K. Willits, S. L. Skornia, J. Biomater. Sci.-Polym. Ed. 2004, 15, 1521.
[109] L. A. Flanagan, Y. E. Ju, B. Marg, M. Osterfield, P. A. Janmey, Neuroreport 2002, 13, 2411.

[110] T. A. Ulrich, A. Jain, K. Tanner, J. L. MacKay, S. Kumar, Biomaterials 2010, 31, 1875.

[111] J. M. Orban, L. B. Wilson, J. A. Kofroth, M. S. El-Kurdi, T. M. Maul, D. A. Vorp, J. Biomed. Mater. Res., Part A 2004, 68A, 756.

[112] N. Inoue, M. Bessho, M. Furuta, T. Kojima, S. Okuda, M. Hara, J. Biomater. Sci.-Polym. Ed. 2006, 17, 837.

[113] M. W. Tibbitt, A. M. Kloxin, K. U. Dyamenahalli, K. S. Anseth, Soft Matter 2010, 6, 5100

[114] Y. L. Wang, R. J. Pelham, Mol. Motors Cytoskeleton, B 1998, 298, 489.

[115] A. Engler, L. Bacakova, C. Newman, A. Hategan, M. Griffin, D. Discher, Biophys. J. 2004, 86, 617.

[116] A. S. Rowlands, P. A. George, J. J. Cooper-White, AM. J. PhysioCell. Ph. 2008, 295, C1037.

[117] Y. Aratyn-Schaus, M. L. Gardel, Curr. Biol. 2010, 20, 1145.

[118] C. M. Lo, H. B. Wang, M. Dembo, Y. L. Wang, Biophys. J. 2000, 79, 144.

[119] K. Saha, A. J. Keung, E. F. Irwin, Y. Li, L. Little, D. V. Schaffer K. E. Healy, Biophys. J. 2008, 95, 4426.

[120] X. Q. Brown, K. Ookawa, J. Y. Wong, Biomaterials 2005, 26, 3123.

[121] V. Vogel, M. P. Sheetz, Curr. Opin. Cell Biol. 2009, 21, 38.

[122] J. A. Crowe-Willoughby, K. L. Weiger, A. E. Ozcam, J. Genzer, Polymer 2010, 51, 763.

[123] A. M. Kloxin, J. A. Benton, K. S. Anseth, Biomaterials 2010, 31, 1.

[124] R. H. Schmedlen, K. S. Masters, J. L. West, Biomaterials 2002, 23, 4325.

[125] C. A. DeForest, E. A. Sims, K. S. Anseth, Chem. Mater. 2010, 22, 4783.

[126] M. Ghibaudo, A. Saez, L. Trichet, A. Xayaphoummine, J. Browaeys, P. Silberzan, A. Buguin, B. Ladoux, Soft Matter 2008, 4, 1836.

[127] E. Mussig, S. Schulz, J. P. Spatz, N. Ziegler, P. Tomakidi, T. Steinberg, Eur. J. Cell Biol. 2010, 89, 315.

[128] C. Boura, S. Muller, D. Vautier, D. Dumas, P. Schaaf, J. C. Voegel, J. F. Stoltz, P. Menu, Biomaterials 2005, 26, 4568.

[129] S. Munevar, Y. L. Wang, M. Dembo, Biophys. J. 2001, 80, 1744.

[130] Y. Aratyn-Schaus, M. L. Gardel, Curr. Biol. 2010, 20, 1145.

[131] R. A. Jannat, G. P. Robbins, B. G. Ricart, M. Dembo, D. A. Hammer, J. Phys.: Condens. Matter 2010, 194117.

[132] J. Lee, M. Leonard, T. Oliver, A. Ishihara, K. Jacobson, J. Cell Biol. 1994, 127, 1957.

[133] O. M. Rossier, N. Gauthier, N. Biais, W. Vonnegut, M. A. Fardin, P. Avigan, E. R. Heller, A. Mathur, S. Ghassemi, M. S. Koeckert, J. C. Hone, M. P. Sheetz, EMBO J. 2010, 29, 1055.

[134] K. A. Addae-Mensah, N. J. Kassebaum, M. J. Bowers, R. S. Reiserer, S. J. Rosenthal, P. E. Moore, J. P. Wikswo, Sens. Actuators, A 2007, 136, 385

[135] Y. Zhao, C. C. Lim, D. B. Sawyer, R. L. Liao, X. Zhang, Cell Motil. Cytoskeleton 2007, 64, 718.

[136] Y. Cao, J. Chen, M. O. Adeoye, W. O. Soboyejo, Mater. Sci. Eng., C: Biomimetic Supramol. Syst. 2009, 29, 119.

[137] S. Petronis, J. Gold, B. Kasemo, J. Micromech. Microeng. 2003, 13,900 .

[138] K. M. Yamada, R. Pankov, E. Cukierman, Braz. J. Med. Biol. Res. 2003, 36, 959.

[139] E. Cukierman, R. Pankov, D. R. Stevens, K. M. Yamada, Science 2001, 294, 1708.

[140] D. L. Coutu, A. M. Yousefi, J. Galipeau, J. Cell. Biochem. 2009, 108, 537.

[141] P. Tayalia, C. R. Mendonca, T. Baldacchini, D. J. Mooney, E. Mazur, Adv. Mater. 2008, 20, 4494.

[142] F. Klein, B. Richter, T. Striebel, C. M. Franz, G. v. Freymann, M. Wegener, M. Bastmeyer, Adv. Mater. 2011, 23, 1341.

[143] G. Vozzi, A. Ahluwalia, J. Mater. Chem. 2007, 17, 1248. 
[144] M. Mattioli-Belmonte, G. Vozzi, K. Kyriakidou, E. Pulieri, G. Lucarini, B. Vinci, A. Pugnaloni, G. Biagini, A. Ahluwalia, J. Biomed. Mater. Res. A 2008, 85A, 466.

[145] M. H. Zaman, L. M. Trapani, A. Siemeski, D. Mackellar, H. Y. Gong, R. D. Kamm, A. Wells, D. A. Lauffenburger, P. Matsudaira, Proc. Natl. Acad. Sci. USA 2006, 103, 10889.

[146] E. Figallo, M. Flaibani, B. Zavan, G. Abatangelo, N. Elvassore, Biotechnol. Prog. 2007, 23, 210.

[147] C. M. Nelson, M. M. VanDuijn, J. L. Inman, D. A. Fletcher, M. J. Bissell, Science 2006, 314, 298.
[148] J. W. Lee, P. X. Lan, B. Kim, G. Lim, D. W. Cho, J. Biomed. Mater. Res., Part $B$ 2008, 87B, 1.

[149] H. Francisco, B. B. Yellen, D. S. Halverson, G. Friedman, G. Gallo, Biomaterials 2007, 28, 3398.

[150] S. H. Cho, S. H. Oh, J. H. Lee, J. Biomater. Sci., Polym. Ed. 2005, $16,933$.

[151] B. C. Isenberg, P. A. DiMilla, M. Walker, S. Kim, J. Y. Wong, Biophys. J. 2009, 97, 1313.

Received: May 13, 2011

Published online: December 9, 2011 